NBER WORKING PAPER SERIES

\title{
UNEMPLOYMENT INSURANCE AND DISABILITY INSURANCE IN THE GREAT RECESSION
}

Andreas I. Mueller

Jesse Rothstein

Till M. von Wachter

Working Paper 19672

http://www.nber.org/papers/w19672

\author{
NATIONAL BUREAU OF ECONOMIC RESEARCH \\ 1050 Massachusetts Avenue \\ Cambridge, MA 02138 \\ November 2013
}

We thank Chris Hansman, Eric Johnson, Jeehwan Kim, and Ana Rocca for excellent research assistance, and David Pattison for generous help with tabulating the administrative micro data files from SSA. Rothstein is grateful to the Russell Sage Foundation and the Center for Equitable Growth at UC Berkeley for financial support. Mueller and von Wachter's research was supported by the U.S. Social Security Administration through grant \#1 DRC120000020100 to the National Bureau of Economic Research as part of the SSA Disability Research Consortium. The findings and conclusions expressed are solely those of the authors and do not represent the views of SSA, any agency of the Federal Government, or the National Bureau of Economic Research.

NBER working papers are circulated for discussion and comment purposes. They have not been peerreviewed or been subject to the review by the NBER Board of Directors that accompanies official NBER publications.

(C) 2013 by Andreas I. Mueller, Jesse Rothstein, and Till M. von Wachter. All rights reserved. Short sections of text, not to exceed two paragraphs, may be quoted without explicit permission provided that full credit, including (C) notice, is given to the source. 
Unemployment Insurance and Disability Insurance in the Great Recession

Andreas I. Mueller, Jesse Rothstein, and Till M. von Wachter

NBER Working Paper No. 19672

November 2013

JEL No. H55,J65

\section{ABSTRACT}

Disability insurance (DI) applications and awards are countercyclical. One potential explanation is that unemployed individuals who exhaust their Unemployment Insurance (UI) benefits use DI as a form of extended benefits. We exploit the haphazard pattern of UI benefit extensions in the Great Recession to identify the effect of UI exhaustion on DI application, using both aggregate data at the state-month and state-week levels and microdata on unemployed individuals in the Current Population Survey. We find no indication that expiration of UI benefits causes DI applications. Our estimates are sufficiently precise to rule out effects of meaningful magnitude.

Andreas I. Mueller

Columbia Business School

3022 Broadway, Uris Hall 824

New York, NY 10027

amueller@columbia.edu

Jesse Rothstein

Goldman School of Public Policy

and Department of Economics

University of California, Berkeley

2607 Hearst Avenue

Berkeley, CA 94720-7320

and NBER

rothstein@berkeley.edu
Till M. von Wachter

Department of Economics

University of California, Los Angeles

8283 Bunche Hall

MC 147703

Los Angeles, CA 90095

and NBER

tvwachter@econ.ucla.edu 


\section{Introduction}

As of the end of 2012, 8.8 million adult Americans received Social Security Disability Insurance (SSDI) benefits. SSDI is a social insurance program that collects mandatory premiums from workers and uses them to pay benefits to former workers who have become disabled. ${ }^{1}$ Figure 1 plots the share of the working-age population receiving SSDI over time. It shows that this share has more than doubled since 1990. The rapid growth has prompted concerns about SSDI's sustainability, and recent projections indicate that the SSDI trust fund will be exhausted in 2016 (Social Security Administration Board of Trustees, 2012).

As Figure 1 indicates, the growth rate of SSDI rolls accelerated during the recessions of the early 1990s and early 2000s, and perhaps during the 2007-2009 recession as well. Figure 2 illustrates the number of applications for SSDI benefits and the number of new awards, both expressed as shares of the civilian noninstitutional population aged 20-64, along with the unemployment rate. Since the 1980s, SSDI applications and awards have risen in downturns, then fallen beginning a year or two after the unemployment peak (Black, Daniel, and Sanders 2002; Autor and Duggan 2003; Duggan and Imberman 2009; Coe et al. 2012). SSDI applications per capita, for example, rose at a 6.7\% annual rate between 1989 and 1994, fell at a 4.6\% annual rate during the expansion years 1994 through 1999, then rose again at an 10.5\% annual rate between 1999 and 2004. Duggan and Imberman (2009) find that between 1984 and 2003 a one percentage point increase in the national

\footnotetext{
${ }^{1}$ Another program, SSI, provides benefits to disabled adults and children based on financial need, regardless of work history. SSI caseloads have also grown rapidly.
} 
unemployment rate was associated with an increase of roughly 8-9 percent in the number of applications filed for SSDI benefits. They conclude that nearly one quarter of the rise in male SSDI participation between 1984 and 2003 can be attributed to the recessions of the early 1990s and early 2000s. ${ }^{2}$ The cyclical pattern is notably weaker after 2004 (von Wachter 2010). Applications declined at only a $0.3 \%$ annual rate between 2004 and 2007 , then grew at a $6.5 \%$ rate - far from proportional to the magnitude of the Great Recession - between 2007 and $2011 .^{3}$

Neither the older strongly countercyclical pattern nor its dampening in the last decade are well understood. One explanation for countercyclical application rates that would be generally consistent with the purposes of the SSDI program is that employers' willingness to hire (and make accommodations for) individuals with moderately work-limiting disabilities may vary with the tightness of the labor market. SSDI eligibility is restricted to individuals with functional impairments that prevent them from performing their previous jobs or from adjusting to other types of work. The worker's age, education, and experience are considered in assessing his or her suitability for alternative employment; as the jobs available to a worker with a given profile likely depend on economic conditions, there may well be workers who meet the medical eligibility criteria in bad economic times who would not be considered to be sufficiently disabled were the labor market tighter. ${ }^{4}$

\footnotetext{
${ }^{2}$ Other contributing factors include an aging population, increased female labor force participation (which increases women's eligibility for SSDI benefits), more generous benefits, rising income inequality, and changes in the disability determination process (Duggan and Imberman, 2009).

3 The slow decline after the 2001 recession is consistent with other evidence that the subsequent expansion was relatively tepid.

${ }^{4}$ In principle, medical eligibility does not depend on the availability of positions, but it seems likely that workers' qualifications are in practice judged relative to labor demand. Joffe-Walt (2013)
} 
Other potential explanations for the cyclical sensitivity of SSDI applications attribute it to moral hazard. Consider a worker with a moderate health problem e.g., back pain - that makes work unpleasant but not impossible. In principle, this worker should not be eligible for SSDI. But if he applies, a generous medical examiner might award him benefits (Joffe-Walt 2013). His decision to apply will depend in part on the generosity of SSDI benefits relative to the market wage that he can command. If a recession reduces his market wage, he may be tipped over into SSDI application (Autor and Duggan 2003; Black, Daniel, and Sanders 2002).

A related hypothesis is that workers use SSDI to insure employment losses rather than wage declines. Displaced workers can generally claim unemployment insurance (UI) benefits. But UI is time-limited and recessions are associated with sharp increases in unemployment duration. Workers who exhaust their UI benefits but who are still unable to find work may turn to SSDI for ongoing income support.

SSDI recipients tend to remain on the program, and out of the labor market, until retirement (Autor and Duggan, 2006). As a result, any use of SSDI as a source of extended unemployment benefits is extremely expensive. Indeed, a back-of-theenvelope calculation, discussed below, suggests that savings from avoided SSDI cases could plausibly finance a large share of the costs of extensions of UI benefits. But little is known about the degree to which SSDI is in fact used in this way.

This paper uses data from the Great Recession and its aftermath to investigate the relationship between UI exhaustion and SSDI applications. Our job." 
analysis takes advantage of a great deal of variability of UI benefit durations during the downturn. Potential benefits reached as high as 99 weeks in 2009, remained high for several years, then declined substantially in $2012 .{ }^{5}$

At each point in this period there was substantial cross-sectional variation,, due to vagaries of state law and to discontinuous triggers in federal programs. This meant that workers laid off at roughly the same time were eligible for very different UI durations depending on the location and exact timing of the layoff, and thus that UI exhaustion rates varied substantially over time and across states. We use this variation to identify the effect of UI exhaustion on SSDI usage, using time-series analyses, state-by-month panels, event studies of weekly SSDI applications surrounding UI extensions, and microdata on unemployed workers to isolate different components of the variation in exhaustion timing.

Several recent papers have explored UI-DI interactions. Lindner and Nichols (2012) use variation in benefit amounts and eligibility criteria to identify the causal effect of UI participation on DI application decisions. The most relevant paper to the current project is Rutledge (2012). With both aggregate state-month application data and microdata from the Survey of Income and Program Participation (SIPP), Rutledge examines the effect of UI benefit duration extensions on SSDI application decisions and allowance rates. He focuses on the effect of a UI extension on the behavior of those who were already claiming UI when the spell was announced.

\footnotetext{
${ }^{5}$ Many models show that UI should be more generous during recessions (e.g., Landais, Michaillat, and Saez 2010), as moral hazard costs are relatively low and consumption smoothing benefits high when unemployment is elevated. A full discussion of optimal UI design is beyond the scope of this paper.
} 
We extend Rutledge's analysis in three important ways. First, our conceptual model views UI extensions as a source of variation in the time to UI exhaustion rather than as a direct determinant of SSDI applications, consistent with a behavioral model in which individuals make decisions based on the benefits available to them without regard to the legal labeling of those benefits. Second, our empirical specifications are closely tied to this conceptual model, and are thus easily interpretable in terms of the determinants of the underlying application decision. This contrasts with Rutledge's specifications, which are not closely aligned to a behavioral model and focus on legal labeling - is an extension in effect or not? rather than on true incentives. Third, we introduce two new data sources that have not been used previously to study UI-DI interactions. We have obtained access to micro administrative SSA data that we use to tabulate weekly SSDI applications and the corresponding award rates. We also use matched Current Population Survey (CPS) samples to examine individual-level determinants of DI receipt.

\section{A simple model of UI-DI interactions}

Autor and Duggan (2003) model the choice between work and SSDI application for marginally disabled workers. They show that some partially disabled workers will stay in their existing jobs, but if displaced will prefer to exit the labor force in order to receive DI benefits rather than to search for a new job at a lower wage. Autor and Duggan interpret the cyclicality of SSDI applications as an indication that there are meaningful numbers of workers of this type.

Autor and Duggan's (2003) model does not incorporate unemployment insurance. We extend their model to do so, drawing on Rothstein's (2011) model of 
UI and job search. In our model, a displaced worker can choose in each period whether to search for work or to remain idle. ${ }^{6}$ Only search can lead to a new job, while a DI application can be submitted only when in the idle state.

Searchers pay search costs $\mathrm{c}_{\mathrm{U}}$ and have a probability f of finding employment each period. They can draw on up to $\mathrm{N}$ periods of unemployment benefits, worth bu per period. By contrast, workers out of the labor force do not pay search costs but have probability 0 of finding employment and cannot draw UI benefits.

In a period that an individual is out of the labor force, he or she may apply for DI benefits by paying an application cost $\mathrm{c}_{\mathrm{A}}$. The probability that an application is successful is p. We assume that DI eligibility decisions are perfectly correlated over time, so that a worker who is rejected once will not later reapply. A worker whose application is successful can draw a per-period benefit of $b_{D I}$ in any future period in which he or she is out of the labor force, until such point as he or she is reemployed.

This basic setup gives rise to a dynamic decision problem with state variables $\mathrm{n} \in\{0,1, \ldots, \mathrm{N}\}$, indexing the number of weeks of UI benefit entitlement remaining, and $A \in\{0 ;-1 ; 1\}$, describing the worker's DI entitlement. $A=0$ indicates a worker who has not applied for DI benefits; $A=-1$ a worker who has applied but been rejected; and $A=1$ a worker who has been awarded benefits. Letting $\delta$ indicate the discount rate, $\mathrm{u}(\mathrm{y})$ the flow utility associated with per-period cash income $\mathrm{y},{ }^{7}$ and $\mathrm{V}_{\mathrm{E}}$ the continuation value of a new job, the utility associated with job search is:

\footnotetext{
${ }^{6}$ As UI benefits are paid only to workers with sufficient work histories who are involuntarily displaced, we focus on workers who prefer work to SSDI application, so will not voluntarily quit existing positions in order to apply for DI benefits.

7 We do not model saving or borrowing.
} 


$$
\begin{aligned}
& V_{U}(n, A)=u\left(b_{U I}\right)-c_{U}+\delta\left[f V_{E}+(1-f) \max \left\{V_{U}(n-1, A), V_{I}(n-1, A)\right\}\right] \text { for } n>0 \text { and } \\
& V_{U}(0, A)=u(0)-c_{U}+\delta\left[f V_{E}+(1-f) \max \left\{V_{U}(0, A), V_{I}(0, A)\right],\right.
\end{aligned}
$$

where $V_{I}$ represents the value of idleness. ${ }^{8}$ This depends on the worker's DI application status. Those who have not yet applied for DI benefits or who have applied but been rejected receive:

$$
\mathrm{V}_{\mathrm{I}}(\mathrm{n}, \mathrm{A})=\mathrm{u}(0)+\delta \max \left\{\mathrm{V}_{\mathrm{U}}(\mathrm{n}, \mathrm{A}), \mathrm{V}_{\mathrm{I}}(\mathrm{n}, \mathrm{A})\right\}, \text { for } \mathrm{A} \in\{0 ;-1\} \text { and any } \mathrm{n} \geq 0
$$

Those who have been approved for DI benefits receive:

$$
\mathrm{V}_{\mathrm{I}}(\mathrm{n}, 1)=\mathrm{u}\left(\mathrm{b}_{\mathrm{DI}}\right)+\delta \max \left\{\mathrm{V}_{\mathrm{U}}(\mathrm{n}, 1), \mathrm{V}_{\mathrm{I}}(\mathrm{n}, 1)\right\}
$$

Finally, the utility of a worker who applies for DI benefits is:

$$
\begin{aligned}
& V_{A}(n, 0)=u(0)-c_{A}+\delta\left[p \max \left\{V_{U}(n, 1), V_{I}(n, 1)\right\}+\right. \\
& \left.(1-p) \max \left\{V_{U}(n,-1), V_{I}(n,-1)\right\}\right] .
\end{aligned}
$$

Figure 3 shows how the worker's policy choice varies with $f$ and $p$, for a particular set of other parameters. First, workers with high job-finding probabilities search for work until they find jobs, even beyond the expiration of their UI benefits. This is the upper area in the figure. Second, in the lower left, workers with low jobfinding probabilities but also low DI award probabilities search for work until their UI benefits are exhausted, then exit the labor force without applying for DI. ${ }^{9}$ Third, workers in the lower right region, with very high DI award probabilities but very low job-finding chances, simply apply for DI immediately after displacement,

\footnotetext{
${ }^{8}$ Because we assume that parameters are stationary, it can be shown that any worker who chooses search with $A=0$ and $n \neq 1$ will also choose search the following period. The max operators in the $V_{U}$ expressions are thus relevant only for $\mathrm{n}=1$.

${ }^{9}$ With the parameter values used, job search is worthwhile for the duration of UI benefits even if the job-finding probability is zero, as the UI benefit is larger than the search cost. If $b_{\mathrm{UI}}$ is low enough relative to $\mathrm{C}_{U}$, however, a policy of exiting the labor force immediately after job loss becomes optimal for low-f, low-p workers.
} 
without ever looking for work. Finally, workers with somewhat lower DI award chances and/or somewhat higher job-finding probabilities search for work until their UI benefits are exhausted, then apply for DI benefits.

It is this last type of worker that could produce a causal effect of UI benefit durations on DI applications, as these workers can be deterred from applying for DI by a UI extension. For some, this is temporary - they will still be jobless at the end of the extended benefits, and will apply to DI then. But others will find jobs during the extended search period, and thus may be permanently diverted from the DI program.

This diversion could be substantial. To see this, suppose that $\{f, p\}$ have a uniform distribution on $[0,0.1] \mathrm{X}[0,1]$ among displaced workers and that other parameters are as in Figure 3. Then 17\% of workers, and 35\% of those who exhaust 26 periods of UI benefits, are of the UI-before-DI type. When UI benefits last for 26 weeks, UI-before-DI workers comprise $83 \%$ of DI applicants and $79 \%$ of DI awardees. The average UI-before-DI DI applicant has a per-period job-finding rate of $1.5 \%$. Thus, some would find jobs if given longer UI benefit durations during which to search. With our parameters, a 26-period extension of UI benefits (to a total of 52 periods) would permit just under one-third of the UI-before-DI workers who would otherwise apply for DI to instead find new jobs before their benefits run out. This would reduce steady-state DI applications and awards by a bit over one-quarter, while increasing UI payments by about $40 \%$.

An effect of this magnitude would be enormously important. Because individuals awarded DI benefits tend to draw them until retirement, the present 
value of a single DI award is around $\$ 300,000$. By comparison, weekly UI payments average around $\$ 300$. Thus, the parameters used in Figure 3 and a uniform distribution of $\{\mathrm{f}, \mathrm{p}\}$ imply that DI savings from a 26-week UI extension would amount to over three times the on-budget cost of that extension. In other words, a UI extension would be self-financing even if the effect on steady-state DI awards were only one-third as large as in this simple simulation.

But the parameters used are just approximations, and the assumption of a uniform $\{f, p\}$ distribution is entirely unsupported. It seems more likely, for example, that $\mathrm{f}$ and $\mathrm{p}$ are negatively correlated. This would increase the share of UIbefore-DI workers, though perhaps also reduce their average job-finding rates. Nonuniformity of the two marginal distributions could offset any such effect. The effect of UI benefit duration on DI applications is thus an empirical question.

\section{Data and DI trends}

We rely on three data sources to measure trends in SSDI application and receipt. First, we use publicly available tabulations from the Social Security Administration (SSA) of SSDI, SSI, or SSDI/SSI applications at the state-by-month level between August 2004 and December 2012.

Second, we obtained access to SSA's Disability Research File, a restrictedaccess micro data file covering the years 2008-2010 and containing observations on individual SSDI applications linked to application outcomes. We use these data to construct a state-by-week panel of application counts. We also calculate eventual award rates for each weekly application 'cohort', using information on awards over the remaining horizon in the sample. 
Third, we use the Annual Social and Economic Supplement (ASEC) supplement to the Current Population Survey (CPS), administered in the spring of each year. ${ }^{10}$ Respondents are asked about their income from various sources in the previous calendar year. Those who report income from Social Security are asked to list reasons for this. We measure SSDI receipt as the presence of positive Social Security income for someone who names "disability" as one of the reasons.

Figure 4 shows trends in the number of disabled worker SSDI recipients from the published SSA data, along with two series computed from the CPS ASEC. One series counts all individuals aged 16 and over who report Social Security disability income. The second excludes those over age 66 (67 after 2009, reflecting an increase in the Full Retirement Age), as disabled individuals above this age receive retirement payments rather than SSDI. The former series matches the administrative records reasonably well, though shows a somewhat flatter trajectory. The latter is notably lower, suggesting both that many recipients continue believing they are receiving disability benefits even after they are formally converted to the retirement program and that the CPS survey misses some true SSDI recipients.

In the analysis below, we identify unemployed workers, aged 20-64, in the basic monthly CPS survey and ask whether the expiration of their UI benefits early in calendar year y is associated with a higher probability of receiving SSDI income in that year. This is made possible by the rotating panel design of the CPS, which means that just under half of the respondents in the $y+1$ ASEC file can be matched to

\footnotetext{
10 The ASEC is often known as the "March CPS." It borrows the March sample from the regular monthly CPS survey, supplementing this with portions of the February, April, and November (of the previous year) monthly CPS samples.
} 
basic CPS interviews in February, March, or April of year y, or in November of year $\mathrm{y}$-1. The CPS is an address-based sample, so matches are only possible for individuals who do not move between surveys. We are able to match around 95\% of ASEC respondents to one of the surrounding monthly surveys. Merges between year-y and year-y+1 ASECs are more difficult, with match rates around 75\%.11

In the basic CPS survey, unemployed workers are asked the reason for their unemployment (e.g., layoff vs. voluntary quit) and the number of weeks that they have been unemployed. We use the former to proxy for UI eligibility and the latter to assign each unemployed individual to the date of displacement. We then use a database of state UI rules, discussed in Section IV, to assign the date that the worker would have exhausted his UI benefits if he was eligible for full benefits and if he drew benefits continuously from the date of displacement until exhaustion.

\section{UI during the Great Recession and its aftermath}

\section{A. Extended UI Programs}

Workers displaced from covered employment with sufficient work histories are generally eligible for up to 26 weeks of regular unemployment insurance benefits. But at times during the last few years, workers who have exhausted their regular benefits might have drawn as many as 53 additional weeks of Emergency Unemployment Compensation (EUC) and as many as 20 more weeks of Extended Benefits (EB), bringing the total as high as 99 weeks. There has been substantial

\footnotetext{
11 This excludes observations that should not match due to the structure of the survey (e.g., those in their second sample rotation in year y). About $1 \%$ of monthly-to-ASEC matches and 6-8\% of ASEC-toASEC matches show discrepancies in age, race, gender, or education. Discrepant observations are discarded.
} 
variation in this maximum over time and across states, resulting from differences in state policies, from changing Federal law, and from "triggers" that conditioned both EUC and EB benefits on state economic conditions.

The EUC program was first authorized in June 2008.12 It initially provided 13 weeks of federally-financed benefits to supplement the regular 26 weeks. At the time, the recession was expected to be relatively brief, and EUC was set to expire in March 2009. As the downturn proved to be deeper and longer lasting than initially expected, EUC was gradually expanded. In November 2008, EUC benefits were extended to 33 weeks in states with unemployment rates above 6 percent and to 20 weeks elsewhere. They were extended again in November 2009, to 34 weeks in low unemployment states and 53 weeks in high unemployment states.

EUC complemented a preexisting program, EB, which was designed to provide supplemental weeks of benefits in times of economic distress. States choose whether to participate in EB and, if they participate, select from a menu of possible triggers that will activate EB benefits. Activation provides 13 weeks of EB benefits (on top of the regular and EUC eligibility), or 20 weeks in states that have adopted a more generous trigger and that have unemployment rates above $8 \%$. The first state to become eligible for EB benefits in the Great Recession was Alaska, in June 2008; five additional participating states became eligible by January 2009 .

The cost of EB benefits is ordinarily split between the state and the Federal government, but the American Recovery and Reinvestment Act of 2009 (ARRA; also

\footnotetext{
12 It resembled other, similar temporary programs created in past recessions. The discussion here draws on Rothstein (2011) and Fujita (2010).
} 
known as the Recovery Act) provided for full Federal funding. After this, a number of states passed legislation to adopt the program or to liberalize their triggers. By May 2009, recipients in 27 states could receive EB benefits, and 11 of these offered 20 weeks of benefits. Eligibility continued to expand, with between 36 and 39 states paying EB benefits through most of late 2009, 2010, and early 2011.

Both EUC and EB benefits were gradually rolled back starting in mid 2011. The EB rollback was largely automatic, due to rules that condition eligibility on not just a high but also a rising unemployment rate. During the aftermath of the recession, unemployment remained high but slowly declined. The number of states paying EB benefits fell through the second half of 2011 and the first half of 2012. By July 2012, only Idaho was still paying benefits; it triggered off in early August.

The major rollback of EUC came in February 2012, when legislation made several changes. First, EUC durations were cut by 6 to 14 weeks, depending on the state unemployment rate (though states with rates between 7 and $8.5 \%$ or above 9\% were unaffected). Second, further cuts were scheduled for September 2012. Third, additional weeks of EUC benefits were provided to high-unemployment states that did not qualify for (or did not participate in) the EB program. This provision provided ten extra weeks in March, April, and May of 2012; none in June, July, and August; and four extra weeks from September onward.

On top of the basic story of haphazard expansion and rollback, additional variation in EUC durations arose from the temporary nature of the program. The program was initially set to expire in March 2009. In February 2009, the ARRA 
extended it through December of that year.13 During 2010, Congress then extended it several times for only a few months each: From December 2009 to February 2010, then to April, to June, and to November 2010. Several of these extensions were retroactive, authorized only after the program had already expired. The first expiration lasted only a few days, but two others lasted for about two weeks each and in June and July 2010 the program was allowed to expire for a full seven weeks. A longer-term extension finally took effect in December 2010.

Figure 5 shows the average, minimum, and maximum number of weeks of benefits available over time through the recession, combining the regular, EUC, and EB programs. This figure is made from a database of UI availability at the state-byweek level, constructed by Rothstein (2011) but updated here to the end of 2012 . Maximum benefit durations reached 99 weeks from late 2009 through mid 2012, and the average state was close to the maximum through much of this period. States began to fall away from the maximum during early 2012 .

The three expirations of the EUC program in 2010 are quite prominent in the figure, as durations fall dramatically in each. However, the sharp declines indicated likely overstate the changes experienced by individual recipients. EUC benefits are divided into tiers - at its peak, the 53 weeks of maximum EUC benefits were divided into four tiers of $20,14,13$, and 6 weeks, respectively. When the program expired recipients were permitted to continue to draw benefits until they exhausted their current tier but could not begin a new tier, while people who exhausted their

${ }^{13}$ ARRA also made UI benefits more generous in a number of ways, including by providing a $\$ 25 /$ week supplement to UI benefits and by exempting the first $\$ 2,400$ of benefits from income taxes. Both provisions were temporary. 
regular benefits were not permitted to enter the EUC program. ${ }^{14}$ This tended to smooth over the expirations, limiting the disruption produced. But the degree of smoothing depended importantly on the exact date of job loss, as this determined the worker's position in the tier structure at the time of EUC expiration.

Each eventual reauthorization provided for the retroactive payment of benefits to individuals who would have received EUC but for the temporary exhaustion. The long-term unemployed are unlikely to have substantial liquid savings or easy access to credit (Gruber 1997), however, so many may have felt serious financial crunches during the expirations.

\section{B. Modeling UI Exhaustion}

The complex history of EUC and EB created a great deal of variation in the duration of UI benefits and thus in the timing of UI exhaustion. Unfortunately, while the Employment and Training Administration (ETA) compiles weekly counts of initial UI claims, no comparable data series is available for exhaustions. We take two approaches to approximating the number of exhaustions.

Our first exhaustion series is constructed from state-by-month level ETA data on the numbers of first payments and final payments in each program and EUC tier. For each state in each month, we compute the number of final payments in any program or tier minus the number of first payments in the EUC tiers or EB. This closely approximates exhaustion, but there are three sources of slippage. First, this

14 100\% federal financing of EB expired each time the EUC program did. Many states conditioned their EB participation on continued federal funding, and cut off EB benefits within a week or two of the June 2010 expiration. EB benefits lost during this period were in general not paid retroactively. 
method incorrectly counts as exhaustions individuals who found new jobs or abandoned their job searches upon the expiration of a particular tier or program but who had more benefits available on another tier or program. Second, when individuals receive their final payments from one program or tier in the last week of a calendar month, the initial payment on the next program or tier appears in the next month's data. This creates excess volatility in measured exhaustions. Third, when EUC benefits were expanded -when new tiers were introduced, when the program was retroactively reauthorized, or when a state triggered on to new benefits - many people received first payments who had not received final payments in the previous week. We estimate negative numbers of exhaustions at these times. These moments are quite useful for identification of UI effects, however, as they represent periods when UI exhaustions were low or zero. We present analyses below that zero in on DI application dynamics surrounding UI extensions.

The solid line in Figure 6 shows the estimated number of UI exhaustions each month, using this method. Exhaustions were fairly stable, at around 210,000 per month, through early 2008. Measured exhaustions turned sharply negative in July and August of 2008, following the creation of EUC. They then became volatile, bouncing around a lower mean through the rest of 2008 and 2009 with two dips into negative terrain following EUC expansions in February 2009 and December 2009-January 2010. Exhaustions spiked enormously during the temporary EUC expiration in June 2010, only to turn negative again in August 2010 after the program was reauthorized. Following this episode, the series has bounced around a level similar to that seen before the recession but higher than the 2008-9 average. 
Although the spikes and negative values represent measurement problems, the broad patterns - declines in exhaustions in 2009-10 followed by an increase in 2011-12 - correspond to real dynamics. In 2009-10, benefit durations were quite long, and many recipients found jobs or exited the labor force before they exhausted benefits, while the cohorts that were approaching exhaustion were primarily those that had lost their jobs before the recession so were not particularly large. In 201112, durations remained long, but the large 2009 cohorts were exhausting their benefits, offsetting the effect of extended durations on the exhaustion rate.

We simulate an alternative UI exhaustion measure to use as a check on the administrative data. We begin with weekly data on initial claims for regular UI benefits by state. We then use our state-by-week database of UI availability to identify the week that each entering UI cohort would have exhausted its benefits, assuming eligibility for full benefits and continuous claiming. Next, we estimate the probability that an individual entering unemployment in each week would have survived in that status (rather than becoming reemployed or exiting the labor force) until the expiration of benefits. The survival probabilities are described in the appendix; they are based on estimated average UI exit hazards that are allowed to vary smoothly over time and discretely with unemployment duration. By multiplying the size of the entering cohort by the survival probability, we estimate the number of UI exhaustions produced by the cohort when its benefits end, then 
aggregate across all cohorts that exhausted their benefits in each month to construct an estimated exhaustion series. ${ }^{15}$

Two series obtained via this method are plotted in Figure 6, corresponding to different definitions of "exhaustion." The first series, plotted as a dotted line, judges an individual to have exhausted her benefits in the first week that she did not receive an on-time benefit payment, even if she was later paid retroactively for that week. This series mirrors the general trends in the administrative measure, but shows zero exhaustions rather than negative numbers in months following EUC introduction and expansions. It also, however, shows an enormous spike in June 2010, when EUC was allowed to expire. (This data point is censored in the graph to control the overall scale; in fact, the series shows nearly 2.5 million exhaustions that month.) It is unclear whether this accurately reflects the expirations that are relevant to SSDI application decisions. If recipients were confident that Congress would eventually reauthorize the program retroactive to its expiration, and if they had access to sufficient credit to borrow against their eventual benefits, this spike dramatically overstates the number of true exhaustions.

Our second simulated exhaustion series, graphed as a dashed line, counts individuals to exhaust their benefits only when they receive their final payments under any program, ignoring temporary breaks that are repaid retroactively. This does not show a pronounced spike in June 2010 but does a better job of mirroring

\footnotetext{
15 There is an additional adjustment to account for the fact that not all claims for UI benefits lead to actual benefit payments.
} 
the patterns in the administrative data in 2011. We use this as our preferred exhaustion series in the analyses below.

Our simulated final exhaustion series explains $9 \%$ of the time series variation in the administrative data measure (and 21\% when June-August 2010 are excluded). There is substantial across-state variation concealed behind the aggregate time series shown in Figure 6. New York, for example, saw essentially zero exhaustions in 2008 and 2009, while Virginia saw as many or more exhaustions each month in 2008 as before the recession. We exploit this variation in many of the estimates below. A natural concern is that the state-by-month exhaustion measures may be particularly noisy at the state-by-month level. However, they do seem to have substantial signal: The elasticity of the administrative data exhaustion measure with respect to simulated final exhaustions, controlling for state and month effects, is 0.24 , with a standard error of 0.03 .16 When we exclude the June - August 2010 period, the elasticity rises to 0.28.

\section{Analyses of UI-DI interactions using aggregate data}

In this section, we present time-series, state-by-month panel data, and stateby-week event studies of the relationship between UI exhaustions and DI applications as well as award rates. Recall that the model in section II suggested that some marginally disabled UI recipients might be induced to apply for SSDI benefits by the impending or actual exhaustion of their UI benefits. This would imply a

\footnotetext{
${ }^{16}$ As an alternative to modeling log exhaustions - there are many zeros at the state-by-month level we normalize monthly exhaustions in each state by the average number of monthly exhaustions in the state in 2005-2007. The elasticity reported in the text is based on the normalized series, which we use for all further analyses.
} 
positive correlation between UI exhaustions and SSDI applications. Insofar as the marginal DI applicants are less likely to be awarded benefits, it should also produce a negative correlation between UI exhaustions and SSDI acceptance rates.

\section{A. Time Series Analyses}

We begin by overlaying our simulated final UI exhaustion series with the number of monthly SSDI applications, in Figure 7. There is little sign in this graph of a positive relationship between UI exhaustions and DI applications. Though UI exhaustions fell to well under half of their usual rate through most of 2009, DI applications rose by about $20 \%$ in late 2008 and early $2009 .{ }^{17}$ UI exhaustions returned to close to their pre-crisis level in late 2010; DI applications plateaued around that time and have remained roughly stable since.

Table 1 presents time-series analyses of the log of seasonally-adjusted aggregate monthly DI applications. The first column includes only the simulated number of final UI exhaustions in the month, measured as a share of their average level during calendar years 2005-2007. The coefficient is negative, the opposite of the expected sign if UI exhaustions lead to DI applications, but is insignificant and small. Column 2 adds a quadratic time trend, while column 3 adds a control for the unemployment rate. The unemployment rate coefficient is positive and quite precisely estimated, indicating that a one percentage point increase in unemployment is associated with a $3.9 \%$ increase in DI applications. The UI

\footnotetext{
17 We seasonally adjust the DI series using state-level regressions of log monthly applications on calendar month dummies, controlling for quadratic time trends, an indicator for observations since February 2009, and the number of weeks in the month. We then sum adjusted state applications to form a national series.
} 
exhaustion coefficient becomes positive and marginally significant $(t=2.01)$ when the unemployment rate is controlled, but is quite small: A doubling of UI exhaustions is associated with only a $1.5 \%$ increase in DI applications.

Column 4 adds several controls: the number of initial UI claims, seen as proxies for economic conditions; an indicator for June-August 2010 observations, when the expiration of EUC makes it difficult to measure perceived UI exhaustions; and an indicator for the period after February 2009. These have essentially no effect on the coefficient of interest.

Column 5 adds the averages of three leads and three lags of UI exhaustions. Each of these might capture true effects of UI exhaustions on DI applications, which need not be exactly contemporaneous. But there is little indication that the contemporaneous specification misses an important part of the response - neither the lag nor the lead is significant, the contemporaneous effect is basically unchanged, and the point estimate of the cumulative effect is almost exactly zero.

Columns 6-8 explore alternative measures of UI exhaustions. In column 6 we use the simulated series for initial exhaustions (the dotted line from Figure 6), while in column 7 we use the exhaustion series computed from administrative records on EUC and EB initial and final payments (the solid line from Figure 6). Neither of these series indicates any relationship between exhaustions and DI applications. Finally, in column 8 we replace the counts of exhaustions with an indicator for the four months in which our simulations suggest that there were zero UI exhaustions, immediately following the introduction of the EUC program in mid 2008 and its 
expansion in late 2009. This specification indicates that DI applications fell about $1.9 \%$ in these months, implying similar responsiveness to that found in columns 3-5.

All told, the specifications in Table 1 indicate that any effect of UI exhaustions on DI applications is quite small and sensitive to the way that exhaustions are measured. By contrast, there is a robust and large relationship between the unemployment rate and DI applications that does not appear to reflect an association between overall unemployment and UI exhaustions.

\section{B. Panel Data Analyses}

We next turn to panel data analyses of log monthly DI applications at the state level, in Table 2. These allow us to control for other factors that influence the time pattern of DI applications, identifying the exhaustion effect from differences across states in exhaustion trends. There is substantial variation in these trends, driven in part by the timing of layoffs and in part by variation in UI availability.

Column 1 begins with a simple specification that includes state and month fixed effects, the unemployment rate, and the state-level index of final UI exhaustions. The unemployment rate coefficient is positive and significant, though somewhat smaller than in Table 1 . The UI exhaustion coefficient is almost exactly zero. Moreover, it is extremely precisely estimated, with a standard error less than half of those in Table 1, and we can thus rule out elasticities of DI applications with respect to UI exhaustions larger than 0.005 .

Columns 2 and 3 explore alternative controls for economic conditions. These have little effect on the results. Column 4 includes lags and leads of the exhaustion index. These are both insignificant, and the point estimates indicate a cumulative 
elasticity of DI applications with respect to exhaustions of only 0.018 . In column 5, we include each of the three leads and three lags of the exhaustion series separately. Point estimates (not shown) indicate a cumulative elasticity of 0.004 , with negative coefficients for the contemporaneous and immediate leads and lags and positive coefficients on the longer leads and lags. This is the opposite of the pattern that one would expect from a causal effect of anticipated or recent past UI exhaustion.

Column 6 excludes the June-August 2010 observations, when UI exhaustions are difficult to define precisely. This has little effect.

There are two sources of variation in our simulated UI exhaustion measure: Variation in the size of entering UI cohorts (i.e., in the number of new claimants) and variation in the duration of UI benefits. We have also created alternative simulations that hold the cohort size constant, so that benefit durations are the only source of variation. When we use these measures as instruments for the original measures, results are quite similar to those seen in Table 2, and the upper bounds of the confidence intervals are if anything smaller.

Finally, columns 7-9 of Table 2 explore our alternative UI exhaustion series. They indicate slightly more positive effects, though they still rule out elasticities larger than 0.006. Moreover, column 9 indicates that DI applications rise in months when new UI extensions take effect, and the confidence interval rules out declines larger than $0.4 \%$. We return to this investigation below.

The published data cannot be used to examine award rates, as awards are reported for the month of final adjudication rather than for the month of initial application. As an alternative, we use the SSA microdata to examine the acceptance 
rate for SSDI applications filed in each state in each month in 2008, 2009, and 2010.18 Table 3 presents results parallel to those in Columns 1, 4, 7 and 8of Table 2 . Each of the specifications shows an insignificant, near zero relationship between DI acceptance rates and UI exhaustions. The only exception is in Column 2, where average exhaustions over the previous three months are significantly but positively related to the acceptance rate, the opposite of the expected sign.

Taken together, the panel data analyses in Tables 2 and 3 offer no sign that DI applications or awards respond to UI exhaustions. We can always rule out application elasticities larger than 0.02 , and most specifications rule out elasticities one-quarter this size.

At this point, it is worth considering how large an effect would need to be to be quantitatively important. One way to approach this is to compare the empirical estimates to the elasticities implied by the toy model in Section II. In that model, a doubling of UI durations reduced steady-state UI exhaustions by about half and steady-state DI applications by a quarter. (The short-run effects would be much larger.) The estimates in Tables 2 and 3, then - if they can be interpreted as causal imply much, much smaller UI exhaustion effects.

Another approach is to compare the cost of UI extensions to the resulting DI savings. As noted earlier, the present value of a DI award is around $\$ 300,000$, while UI benefits cost around $\$ 300$ per week. Thus, if extending UI benefits by one week

\footnotetext{
${ }^{18}$ Appendix Table A.1 reports application analyses conducted using only the period covered by the microdata. Results are similar to those in Table 2.
} 
diverts even one in one thousand recipients from going on DI, the DI savings would pay the entire cost of the UI extension.

However, the first-order effect of a UI extension is likely to be to merely delay DI applications rather than to permanently displace them. Rothstein (2011) estimates that the long-term unemployed had monthly job-finding rates around 10 percent through 2009 and 2010. If we suppose that marginal DI applicants have similar job-finding rates to this and if we assume a DI award rate of one-third, roughly matching the recent average, then a four-week UI extension would be fully financed through DI savings if it deterred 120 DI applications per 1,000 potential UI exhaustees. This almost certainly understates the needed amount of deterrence, as marginal DI applicants are probably less employable than the average long-term UI recipient and likely have lower award rates than average DI applicants.

Recall that the estimates in Table 2 always ruled out elasticities of DI applications with respect to UI exhaustions larger than 0.02. DI applications are of the same rough order of magnitude as UI exhaustions, so this implies a reduction of not more than 20 DI applications per 1000 UI exhaustees whose benefits are extended, well below the break-even point. Moreover, this is based on the upper limit of the confidence intervals; point estimates imply zero or even negative effects.

\section{Event Analyses}

We next use our administrative micro data to conduct event studies of weekly DI applications in the periods immediately surrounding extensions of UI benefits. These have several potential advantages over the analyses above. First, they do not require us to rely on our imperfect UI exhaustion measures; we can be 
confident that UI exhaustions declined drastically following new benefit extensions. Second, the event study framework allows us to more flexibly examine the time pattern of any application responses to UI extensions. Third, the only lever by which UI exhaustion might be manipulated is the extension of UI benefits, so reduced-form event studies of UI extensions are directly informative about policy effects. ${ }^{19}$

In implementing the event study, we face two challenges. First, we cannot identify the individuals at risk of UI exhaustion in DI data. Thus, as above, we examine the effect of UI extensions on aggregate DI applications. Second, many states saw repeated UI extensions over relatively short periods in 2008 and 2009, which makes it difficult to distinguish long-run effects of one extension from shortrun effects of the next. Thus, while a full assessment of the impact of UI extensions would consider the cumulated net effect, starting from the date that the extension is first anticipated and extending until well after the last cohort affected by the extension exhausts its UI benefits, we focus on shorter-run impacts and on extensions that do not closely overlap.

We define event dates as the weeks on which UI extensions came into effect, as reported in "Trigger Notices" published by the U.S. Department of Labor. We estimate specifications of the form:

$$
\log \left(N A P P_{s t}\right)=\alpha+\gamma_{s}+\theta_{t}+\sum_{k \geq-4}^{N} \delta_{k} D_{s t}^{k}+\beta X_{s t}+\epsilon_{s t}
$$

\footnotetext{
${ }^{19}$ One can interpret the event study estimates as the 'reduced forms' corresponding to 2SLS estimators in which UI benefit extensions are used as instruments for UI exhaustion. We discussed 2SLS estimates like this above.
} 
where $N A P P_{s t}$ represents the log of the number of SSDI applications filed in state $\mathrm{s}$ in week t. $\theta_{t}$ and $\gamma_{s}$ are time and state fixed effects, respectively. $\delta_{k}$ measures the difference from the national weekly trend k weeks after (or $|\mathrm{k}|$ weeks before, when $\mathrm{k}<0$ ) the event date, and $\mathrm{N}$ is the number of weeks the extension was in place. $\mathrm{X}_{\mathrm{st}}$ contains polynomials of degree three for the state-level unemployment rate as well as the state-level insured unemployment rate. Note that the state-level unemployment rate is only available at the monthly frequency.

Figure 8 shows the $\delta_{k}$ coefficients for the four weeks immediately preceding and following an extension in UI durations. Panels A and B show estimates for log weekly SSDI applications, the first using both short extensions (often providing only 6 weeks of additional benefits) and the second using only extensions of 13 weeks or more, while Panels C and D show estimates for award rates. The corresponding coefficients, standard errors, and p-values are shown in Appendix Table A.2.

We begin with the results for DI applications, in Panels A and B. These show an uptake in SSDI applications prior to UI extensions, relative to the average 5 weeks or more before the extension. This is robust to a range of alternative specifications. We would not expect much of an anticipation effect, as many extensions were not easily predicted; moreover, this is the opposite of the expected sign. We are concerned that the effect may reflect uncontrolled variation in economic conditions that leads both to "triggering" UI extensions and to increases in SSDI applications. However, the effect disappears when we restrict attention to non- 
overlapping extensions, shown as dashed lines. ${ }^{20}$ We therefore put more emphasis on these results.

The solid lines drop slightly after extensions take effect, both in Panel A and Panel B. We can reject the hypothesis that the effects during the week of the extension and in the four weeks after the extension are jointly zero, and several of the individual coefficients are statistically significantly different from the preextension average. The estimates based on non-overlapping extensions, however, show no drop in DI applications (save for a small, statistically insignificant dip in the week of the extension).

Overall, the event study paints a mixed picture of the effect of UI extensions on SSDI application rates. On the one hand, the results that include all extensions suggest that there might be modest negative initial effects on SSDI applications, averaging around 2.5 percent (relative to the immediate pre-extension levels) over weeks 0 to 4 . As exhaustion rates fall to zero during this period, this is somewhat larger than, though broadly consistent with, the upper bound of the confidence intervals we obtained in the panel data analysis above. It is still well below the break-even point. On the other hand, these effects are absent for non-overlapping extensions, which are both more clearly exogenous and easier to interpret as policy experiments. Overlapping extensions might have no immediate effect on UI exhaustions if prior extensions have already ensured zero exhaustions in the short term, so it is surprising that these extensions appear to drive the effects we see.

\footnotetext{
20 To be precise, we define an overlapping extension as an extension that follows an earlier $\mathrm{x}$ week extension by less than $\mathrm{x}$ weeks, for any $\mathrm{x}$.
} 
Panels C and D of Figure 8 repeat the event study analysis for SSDI award rates, computed as the share of applications that lead to eventual awards. ${ }^{21}$ There is no sign of a systematic effect of UI extensions on award rates along any dimension.

An advantage of the individual level SSA data is that they permit us to disaggregate the analyses by demographic groups. Figure 9 shows event-study estimates for three major age groups, focusing on large, non-overlapping extensions. Estimates show no sign of systematic effects. Negative post-extension coefficients are nearly all for the youngest age group, which contributes the smallest share of DI applications, and are never significant (individually or jointly). ${ }^{22}$ This confirms our interpretation of the event studies as consistent with the panel data analyses in indicating little overall effect of UI extensions on SSDI applications. The lower panel of Figure 2 shows the effect on the acceptance rate by age group. Again, estimates are noisier for the youngest group but close to zero for the middle and older groups.

\section{Analysis of UI-DI interactions using Current Population Survey microdata}

All of the above analyses are ecological, aiming to tie trends in aggregate DI applications and awards to trends in UI exhaustion. As a final exercise we turn to our merged CPS microdata to examine the individual-level relationship between UI exhaustion and DI receipt.

Table 4 presents summary statistics for the merged CPS sample, pooling data for calendar years 2005 - 2011 (with ASEC observations from the 2006-2012

\footnotetext{
${ }^{21}$ Our data capture only awards made in 2010 and earlier. As a result, there is some censoring in our data. This should be captured by the calendar time effects in our event-study specification.

22 The only statistically significant post-extension coefficient is for the acceptance rate of applications filed by 50-64 year olds two weeks after an extension, and this is positive.
} 
surveys). We restrict the sample throughout to individuals aged 20-64 (in the base month survey), and we those whose unemployment spells started in 2003 or earlier.

The first column presents statistics for the full sample $(\mathrm{N}=240,163) .75 \%$ are employed at the initial monthly survey (generally in March of year y, though some are from February or April, or from November of year y-1), 5\% are unemployed, and $21 \%$ are out of the labor force. The subsample of unemployed workers is described in column 2, while column 3 summarizes job losers. Unfortunately, we cannot measure UI receipt directly. However, the reason for unemployment appears to be an adequate proxy: Of those who were unemployed at the initial monthly survey and said that they had been involuntarily displaced, $40 \%$ report on the following March's ASEC survey having positive UI income for the year. This compares to only $9 \%$ of those who say that they had voluntarily left their previous job or were new entrants or reentrants to the labor force.

Column 4 presents statistics for UI-eligible workers who would have exhausted their benefits before the end of the year in which they were initially observed, had they remained unemployed for that long. (Of course, not all workers reached that point - some presumably were reemployed before exhausting their benefits. But we cannot measure these transitions.) All UI recipients in 2005-2007 are in this category, as the base surveys were completed by April and UI benefits lasted only 26 weeks in those years. In later years, only workers who had already been unemployed for some time by the initial survey were at risk of exhausting their UI benefits within the calendar year. 
Of the UI eligible workers in the base month survey, 57\% would have exhausted their benefits by the end of the calendar year, and $37 \%$ would have exhausted them by the midpoint of the year. The potential exhaustees closely resemble the overall pool of UI eligible workers in their demographic characteristics. The average time of expiration is in early March of year $\mathrm{y}$.

The final rows of the table show the share of individuals who report in the year-y+1 ASEC survey having received SSDI income during year $y$. This is $3.2 \%$ for the full sample, but over half of these also reported having SSDI income in year y-1. We exclude them from our analysis of the effect of UI expiration. Only $1.4 \%$ of individuals who did not have SSDI income in year y-1 had it in year y. Unemployed workers and particularly job losers have below-average SSDI receipt rates. Among UI recipients, those who would have exhausted their benefits before the end of year y have somewhat higher SSDI recipiency rates than do those whose benefits would have continued beyond the end of the year.

Table 5 presents our analysis of UI expiration and DI receipt in the matched CPS-ASEC sample. We estimate specifications of the form:

$$
\mathrm{DI}_{\text {isy }}=\operatorname{logit}\left(\mathrm{UR}_{\text {sy }} \beta+\mathrm{LF}_{\text {isy }} \gamma+\mathrm{X}_{\text {isy }} \delta+\mathrm{D}_{\text {isy }} \theta+\kappa_{\mathrm{s}}+\pi_{\mathrm{y}}\right) \text {, }
$$

where $\mathrm{DI}_{\text {isy }}$ is an indicator for receipt of SSDI income by individual $\mathrm{i}$ in state $\mathrm{s}$ in year $y$ (as reported on the $y+1$ ASEC survey); $U_{s y}$ is the unemployment rate in state $s$ in year $y$; $L F_{i s y}$ is a vector of measures of the individual's labor force status, including dummies for unemployment and NILF (employment is the excluded category) and measures of unemployment duration; and $\mathrm{X}_{\text {isy }}$ is a measure of UI exhaustion before the end of year t. $\mathrm{D}_{\text {isy }}$ is a vector of demographic controls - dummies for ages 40-49, 
50-54, 55-59, and 60-64, with 20-39 the excluded category; a linear age control; and a gender indicator. $\kappa_{\mathrm{s}}$ and $\pi_{\mathrm{y}}$ are fixed effects for states and years, respectively.

Column 1 presents a specification that includes only the demographic controls, state and year FEs, and the state unemployment rate. The latter enters with a negative coefficient, though it is insignificant and the implied effect is very small. Column 2 adds indicators for four labor force statuses at the base survey: Unemployed due to job loss, unemployed due to voluntary quit or to labor market entry or reentry, non-participation in the labor force due to disability, and nonparticipation for other reasons. (The excluded category is employment.) Those who are not employed at the base survey have substantially higher probabilities of receiving SSDI than are the base-survey employed. Those out of the labor force have higher probabilities than the unemployed, particularly so for those who attribute their non-participation to disability.

Logit coefficients can be difficult to interpret, particularly when positive outcomes are rare. We thus use the coefficients to predict how much lower the SSDI receipt rate would be if these individuals had instead been employed. These estimates, reported in the bottom rows of Table 5, indicate that unemployment accounts for two-thirds of the observed 0.97 percentage point rate of DI receipt among the unemployed.

Column 4 adds the unemployment duration (measured as of the end of the calendar year, assuming that the initial unemployment spell lasts until then), alone and interacted with UI eligibility. Those who are employed or out of the labor force at the base survey are assigned durations of 0 . The longer-term unemployed are 
more likely to receive SSDI income than are those unemployed for shorter periods, particularly among job-losers.

Column 5 adds two UI expiration measures. The first is a continuous measure of time (in years) from the date of UI expiration to the end of the focal year. Those whose benefits continued beyond the end of the focal year are coded as zeros. The second measure is an indicator for an expiration before June 30. Because DI applications take several months to process, an individual whose UI benefits expired late in the year and who applied for SSDI immediately thereafter would be unlikely to receive DI income in that calendar year. Those whose applications were filed early in the year, however, should have reasonable probabilities of receiving DI income by the end of the year. Thus, if UI expirations lead in relatively short order to DI applications and if some of those applications are successful, both variables should be positively associated with DI receipt. ${ }^{23}$

The estimates do not indicate this. Expiration before June 30 has a positive coefficient while the continuous time since UI expiration is negative, but they are not individually or jointly $(\mathrm{p}=0.84)$ significant, and both are quite small. The coefficients imply that delaying all UI exhaustions beyond the end of the focal year would reduce DI receipt among the unemployed by only 0.01 percentage points. This result is unaffected by the addition of quadratic and cubic terms in the state unemployment rate, in column 6.

\footnotetext{
${ }^{23}$ Implicit in this parameterization is an assumption that the probability of DI receipt rises with the time elapsed since the DI application, perhaps particularly quickly around 6 months after the initial application.
} 
Column 7 restricts the sample to the unemployed and column 8 to job losers. These dramatically reduce the sample size, reducing precision. Point estimates indicate somewhat larger exhaustion effects - in the final column, they suggest that expiration of UI benefits raises the probability of DI receipt among the UI-eligible unemployed by 0.32 percentage points.

Recall that Figure 6 indicated that approximately 250,000 individuals exhaust their UI benefits each month. The estimate in column 8 of Table 5 indicates that this induces about 800 DI awards over the next 6-12 months. This should be inflated by perhaps $50 \%$ to account for awards made on appeal, for a total of 1,200 eventual induced awards. ${ }^{24}$ This is about $1.4 \%$ of the average number of awards per month in recent years. This figure is strikingly consistent with the application elasticities obtained from the aggregate analyses above, and again indicates that any effects of UI exhaustion on DI uptake are quite small relative to the overall flow.

\section{Conclusion}

This paper has used the uneven extension of UI benefits during and after the Great Recession to isolate variation in UI exhaustion that is not confounded by variation in economic conditions more broadly. Using a variety of analytical strategies, we have examined the relationship between UI exhaustion and uptake of DI benefits. None of the analyses presented here indicate a meaningful relationship. Although we cannot rule out small effects, all of the analyses indicate that the

\footnotetext{
${ }^{24}$ Benítez-Silva et al. (1999) estimate that $46 \%$ of applicants are awarded benefits in the first stage of review and that this rises to $73 \%$ after appeals. First-stage awards are made in 5 months, on average, but awards made on appeal take an average of 15 months.
} 
elasticity of DI applications with respect to UI exhaustion is 0.02 or smaller, far too small to account for the cyclical pattern of DI application or to contribute meaningfully to the cost-benefit analysis of UI extensions.

There are a number of caveats to this result. Most importantly, we must make assumptions about the timing of DI applications and awards induced by UI exhaustion. For the aggregate analyses, we must assume that any induced applications occur within three months (before or after) the date of UI exhaustion, while our CPS analysis can detect only induced applications that lead to receipt of payments within the same calendar year as an earlier UI exhaustion. There may be effects at longer lags - UI exhaustees may wait six months or more before applying for SSDI, or awards made to exhaustees might be disproportionately likely to require an appeal of an initial rejection. These possibilities mean that a causal link between UI exhaustion and DI cannot be conclusively ruled out.

Nevertheless, the analysis here counsels against the likelihood of such a link. It rather tends to support alternative explanations for the countercyclicality of DI applications. For example, the cyclical pattern may simply reflect variation in the potential reemployment wages of displaced workers (Davis and von Wachter 2011) or changes in the employment opportunities of the marginally disabled that influence SSA's evaluation of the applicant's employability. These alternative explanations may have quite different policy implications than would a link to UI. It is not clear, for example, that more stringent functional capacity reviews would reduce recession-induced DI claims if these claims reflect examiners' judgments that the applicants are truly not employable in the extant labor market. 


\section{References}

Autor, David H. and Mark G. Duggan. 2003. The rise in the disability rolls and the decline in unemployment. Quarterly Journal of Economics 118, no. 1:157-206.

Autor, David H. and Mark G. Duggan. 2006. The growth in the Social Security disability rolls: A fiscal crisis unfolding. Journal of Economic Perspectives 20, no. 3:71-96.

Black, Dan, Kermit Daniel, and Seth Sanders. 2002. The impact of economic conditions on participation in disability programs: Evidence from the coal boom and bust. American Economic Review 92, no. 1:27-50.

Coe, Norma B., Kelly Haverstick, Alicia H. Munnell, and Anthony Webb. 2011. What explains state variation in SSDI application rates? Working Paper no. 201123, Center for Retirement Research at Boston College.

Davis, Steven J. and Till von Wachter. 2011. Recessions and the costs of job loss. Brookings Papers on Economic Activity, Fall: 1-61.

Duggan, Mark and Scott A. Imberman. 2009. Why are the disability rolls skyrocketing? The contribution of population characteristics, economic conditions, and program generosity. In Health at older ages: The causes and consequences of declining disability among the elderly, ed. David M. Cutler and David A. Wise. Chicago: University of Chicago Press.

Fujita, Shigeru. 2010. Economic effects of the unemployment insurance benefit. Business Review (Federal Reserve Bank of Philadelphia), Fourth Quarter.

Joffe-Walt, Chana. 2013. Unfit for Work: The Startling Rise of Disability in America. Planet Money for This American Life. http://apps.npr.org/unfit-for-work/ (accessed March 22, 2013).

Landais, Camille, Pascal Michaillat, and Emmanuel Saez. 2010. Optimal unemployment insurance over the business cycle. Working Paper no. 16526, National Bureau of Economic Research, Cambridge, MA.

Lindner, Stephan and Austin Nichols. 2012. The impact of temporary assistance programs on disability rolls and re-employment. Working Paper no. 2012-2, Center for Retirement Research at Boston College.

Rothstein, Jesse. 2011. Unemployment insurance and job search in the Great Recession. Brookings Papers on Economic Activity, Fall: 143-214.

Rutledge, Matthew S. 2012. The impact of Unemployment Insurance extensions on Disability Insurance application and allowance rates. Working Paper no. 2011-17, Center for Retirement Research at Boston College (revised April 2012).

Social Security Administration Board of Trustees. 2012. The 2012 Annual Report of the Board of Trustees of the Federal Old-Age and Survivors Insurance and Federal Disability Insurance Trust Funds. Technical Report GPO 73-947. Washington, DC: U.S. Government Printing Office.

von Wachter, Till. 2010. The effect of local employment changes on the incidence, timing, and duration of applications to Social Security Disability Insurance. Working Paper no. NB10-13, National Bureau of Economic Research Papers on Retirement Research Center Projects, Cambridge, MA. 
Figure 1. DI recipients as share of civilian noninstitutional population aged 20-64, 1970-2011

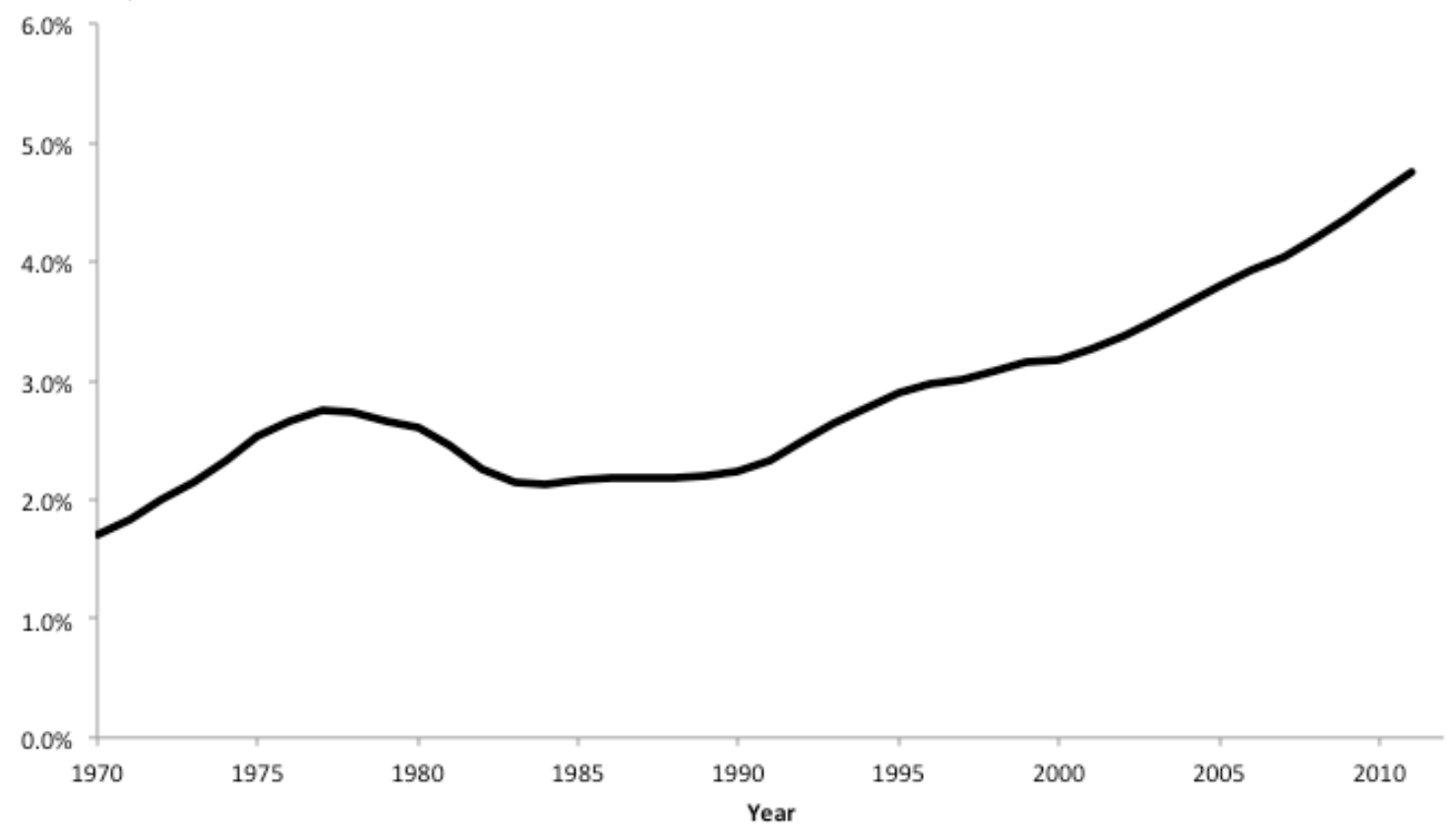

Notes: DI recipients include disabled workers and spousal beneficiaries, and are measured as of December 31 of each year.

Sources: Social Security Administration, Office of the Actuary, and Bureau of Labor Statistics 
Figure 2. SSDI applications and awards as share of population aged 20-64, 1965-2011

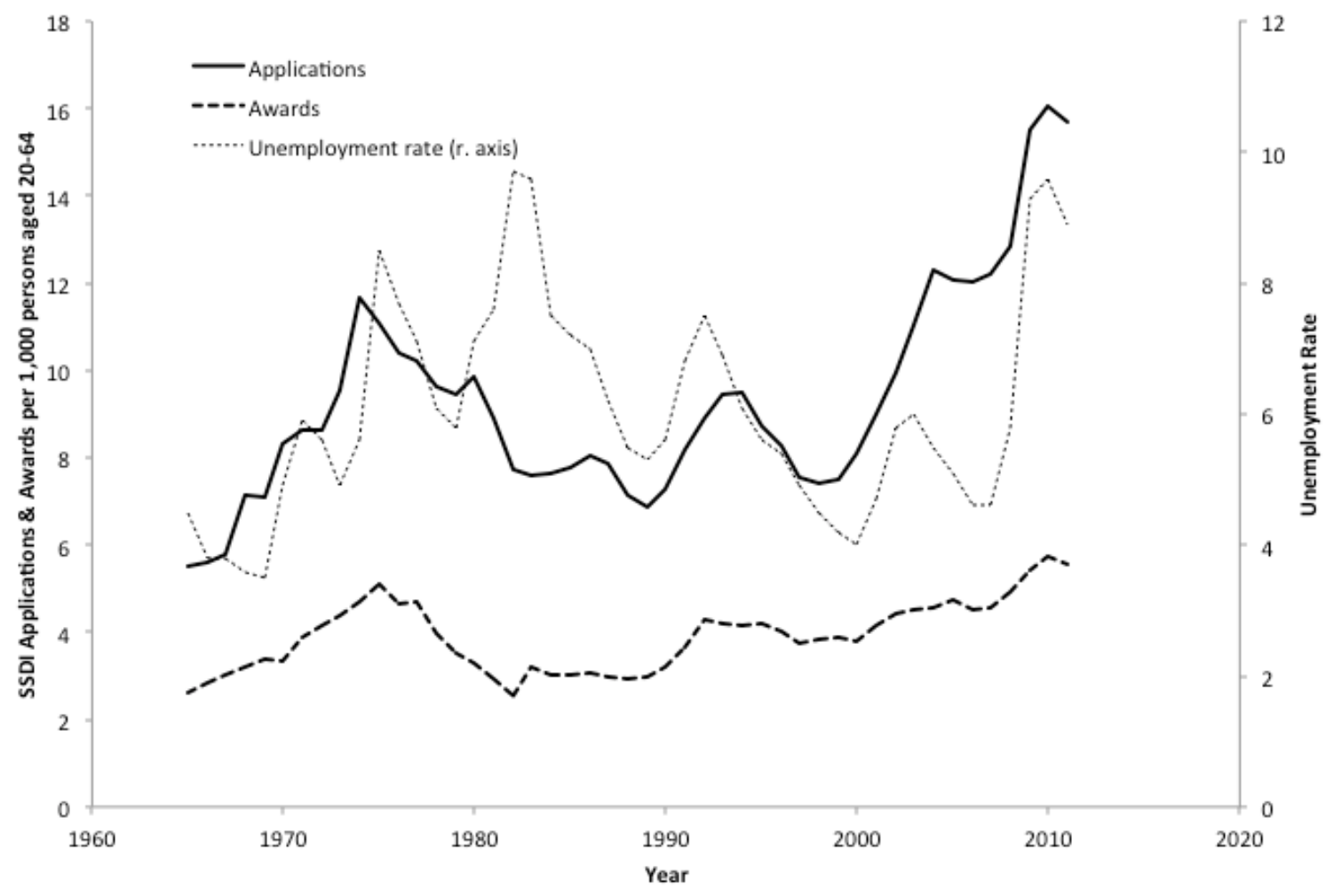

Notes: Applications and awards data apply to new disabled worker cases.

Sources: Social Security Administration, Office of the Actuary, and Bureau of Labor Statistics 
Figure 3. Worker policies by degree of disability (p) and job-finding probability (f)

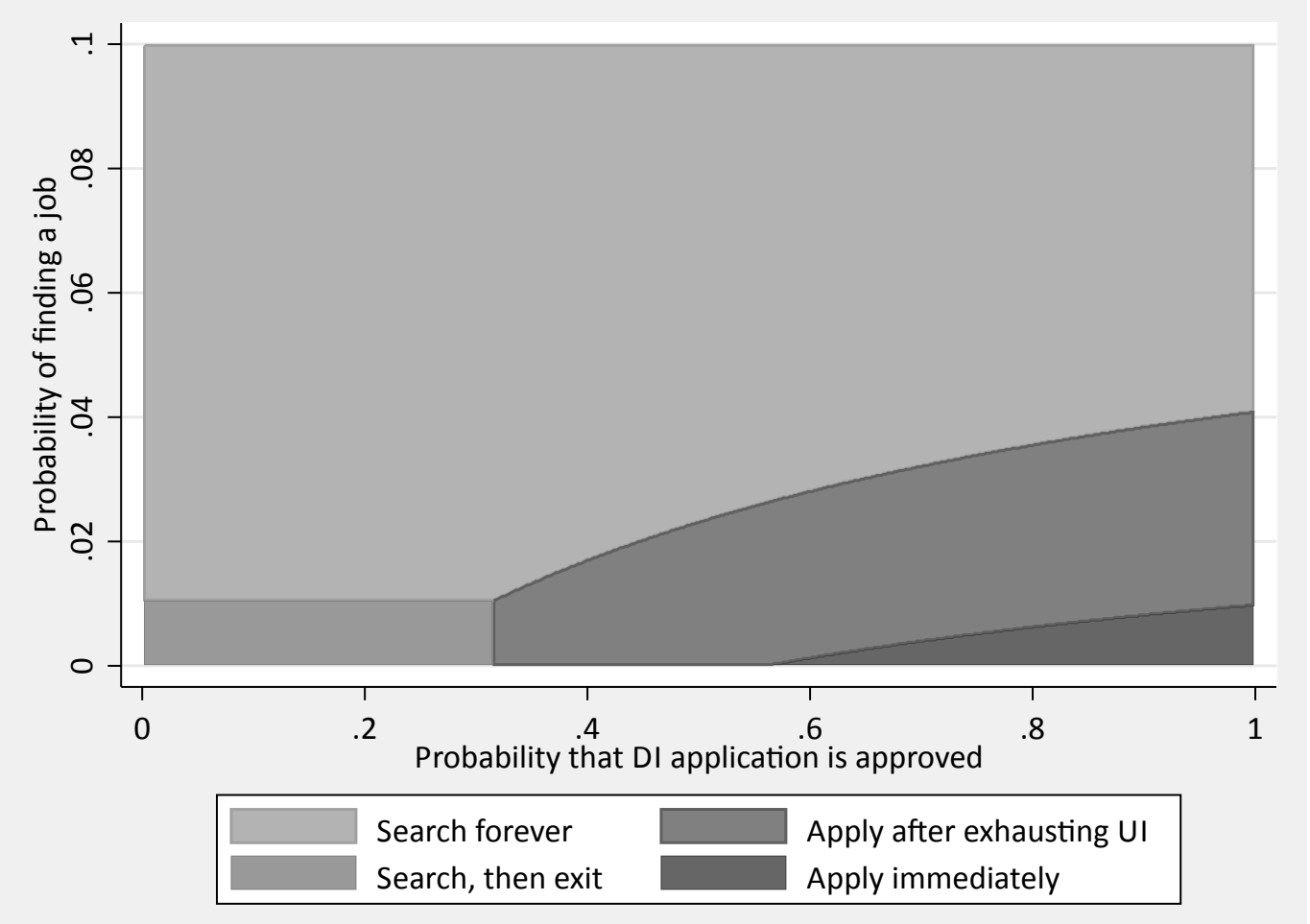

Notes: See text for description of model. Other model parameters are $V_{E}=1 /(1-\delta)$ (corresponding to a per-period wage normalized to 1 and a job that lasts forever); $\mathrm{b}_{\mathrm{UI}}=0.4 ; \mathrm{b}_{\mathrm{DI}}=0.5 ; \mathrm{c}_{\mathrm{U}}=0.2 ; \mathrm{c}_{\mathrm{A}}=3 ; \delta=0.95$; and $\mathrm{u}(\mathrm{y})=\mathrm{y}$. 
Figure 4. SSDI recipients, SSA data vs. CPS ASEC

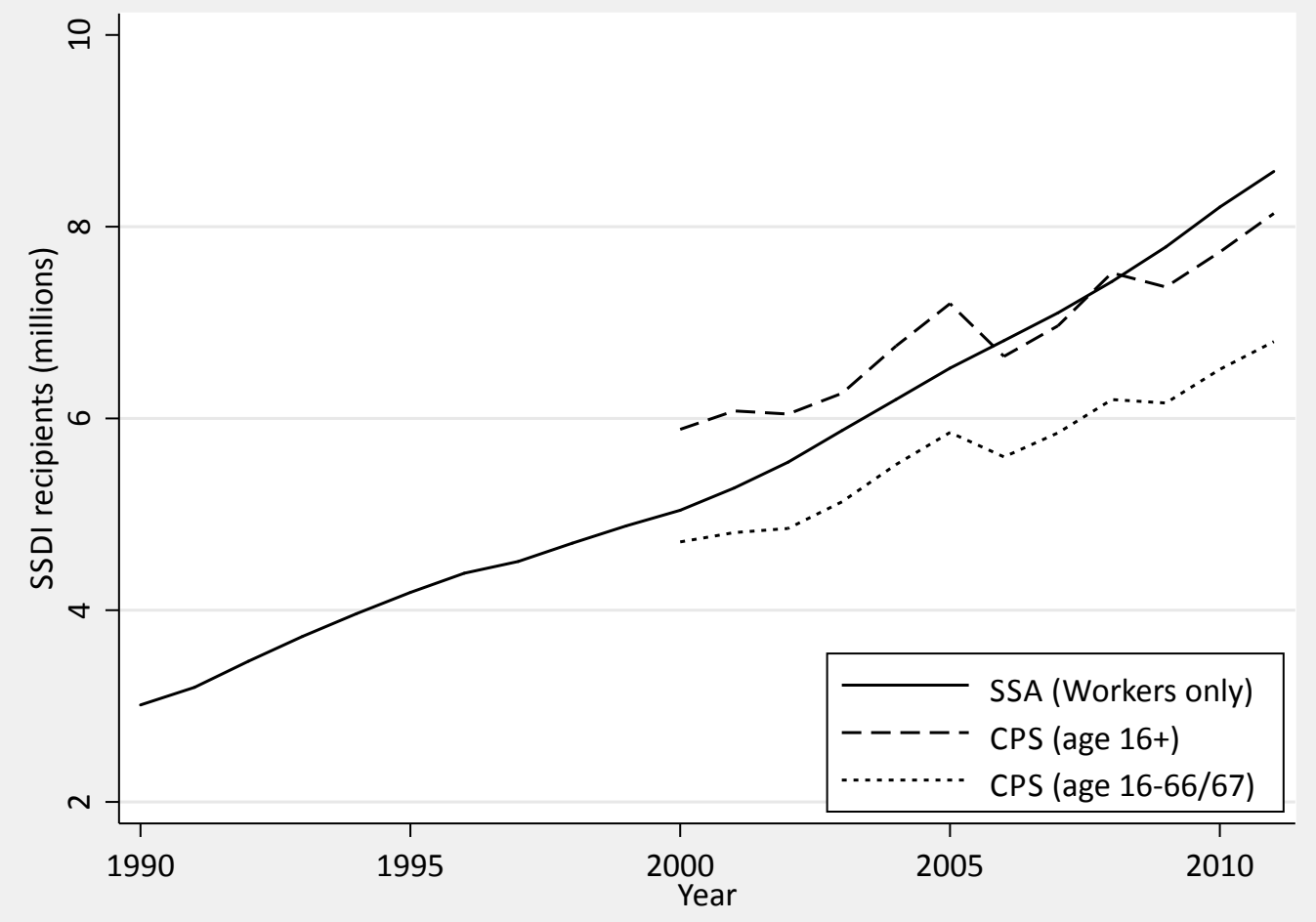

Notes: SSA series includes only disabled worker cases. 
Figure 5. Unemployment insurance benefit availability over the Great Recession

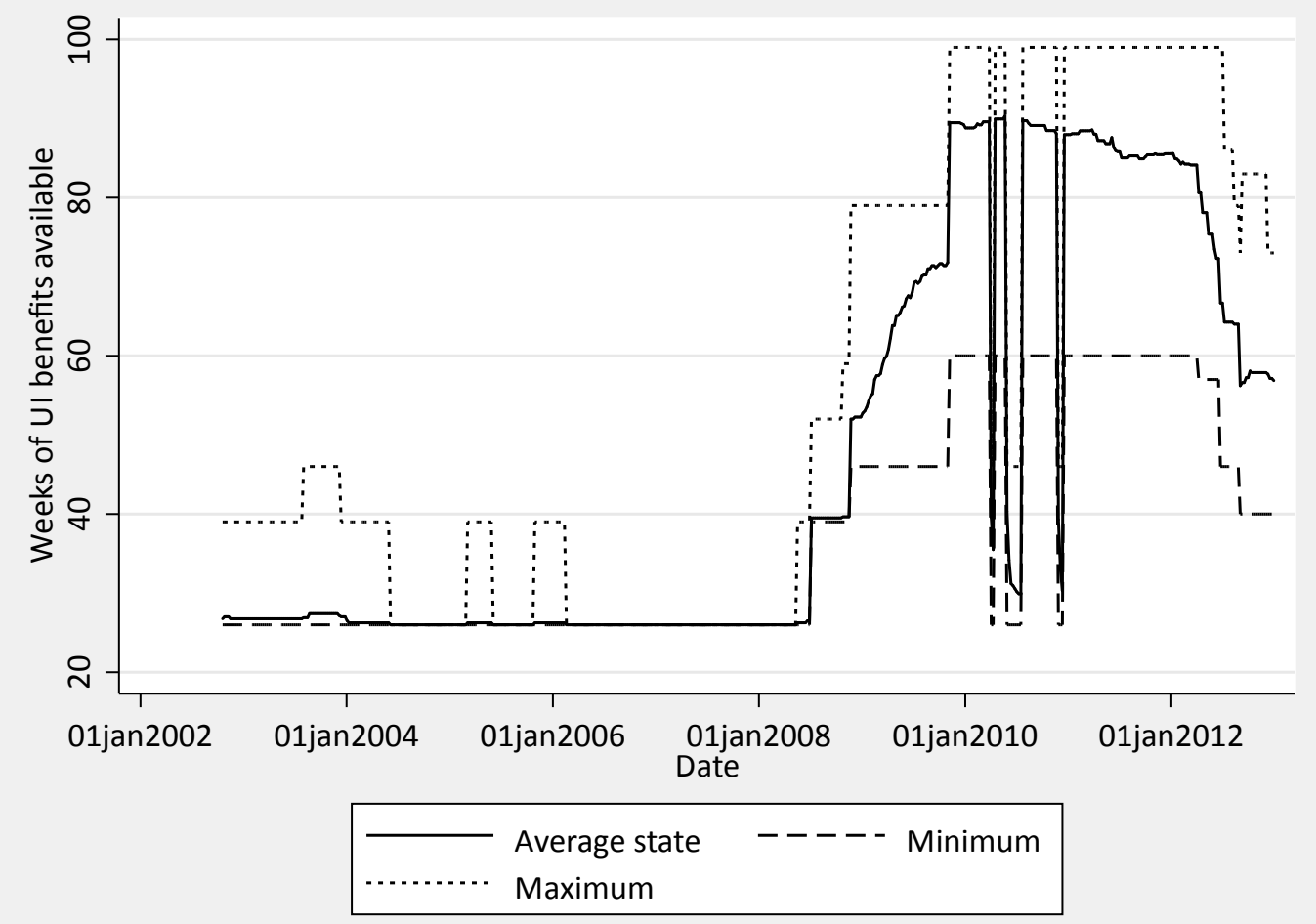

Notes: "Average state" series represents a simple, unweighted average across 50 states plus the District and Columbia. 
Figure 6. Estimates of the number of UI exhaustions per month, 2004-2012.

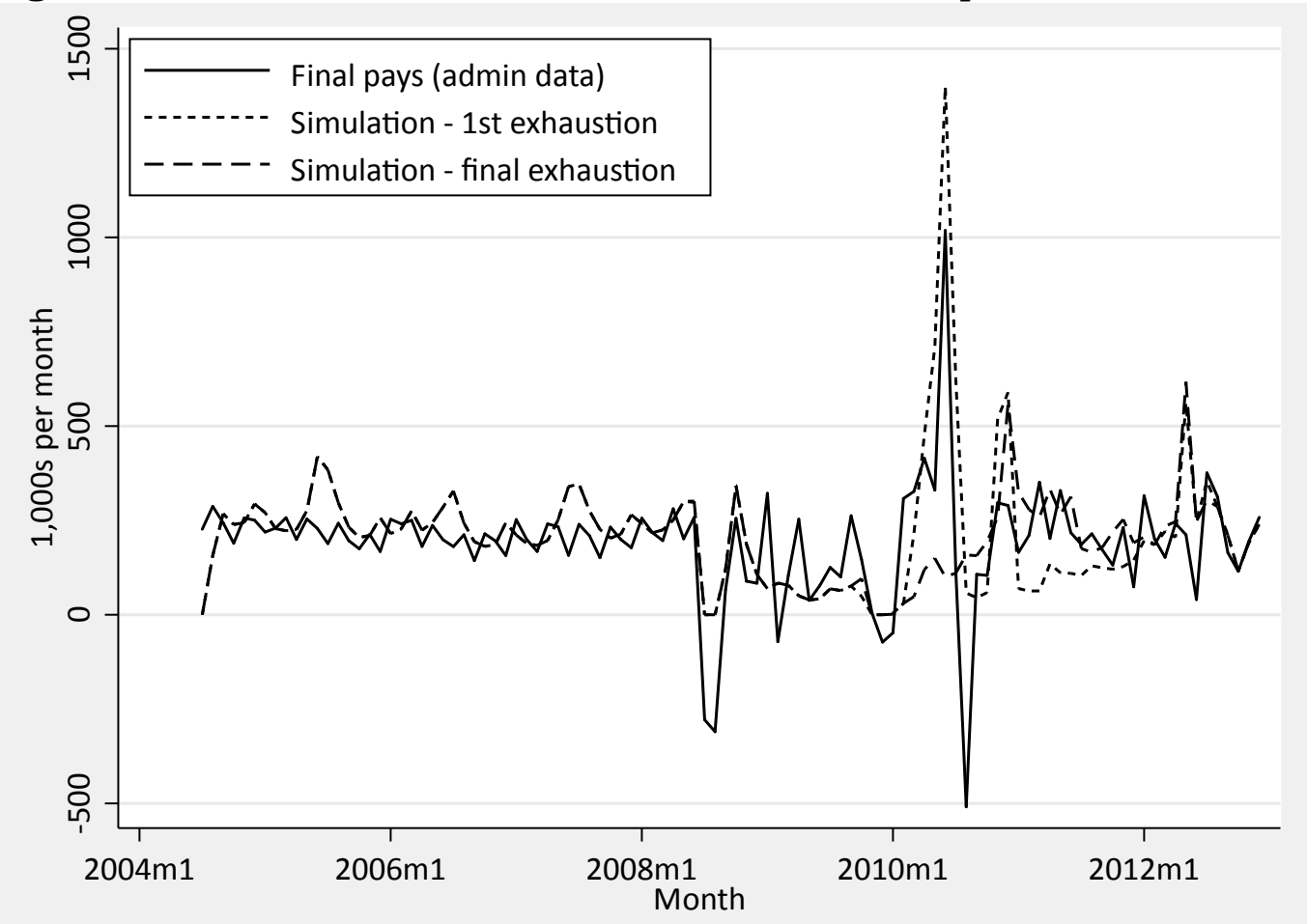

Notes: "Simulation $-1^{\text {st }}$ exhaustion" series is censored at 1.4 million in June 2010; true value is 2.46 million.

Figure 7. UI exhaustions and SSDI applications by month, 2004-2012

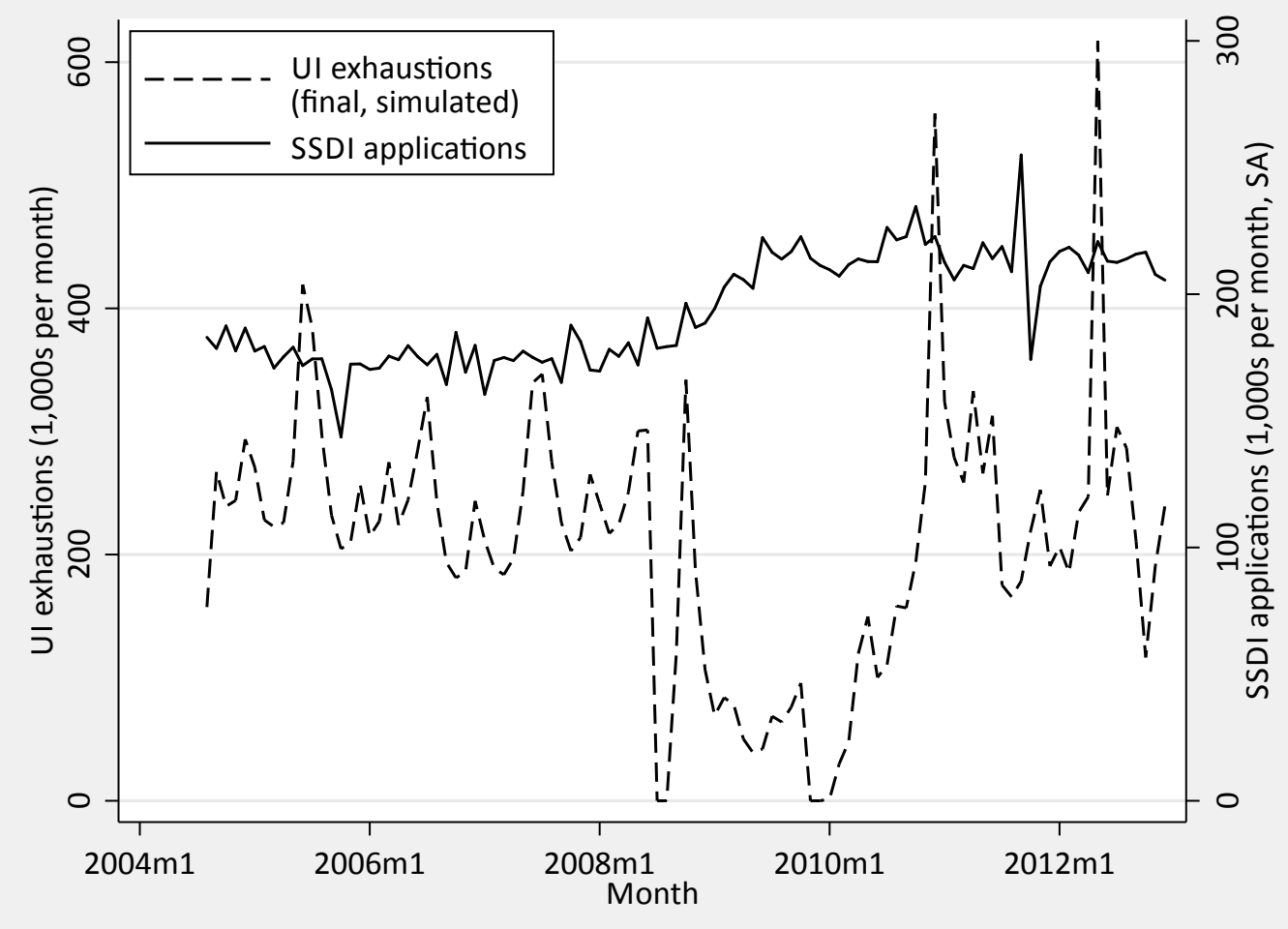


Figure 8. UI event studies

(a) $\log ($ SSDI Applications) - All Extensions

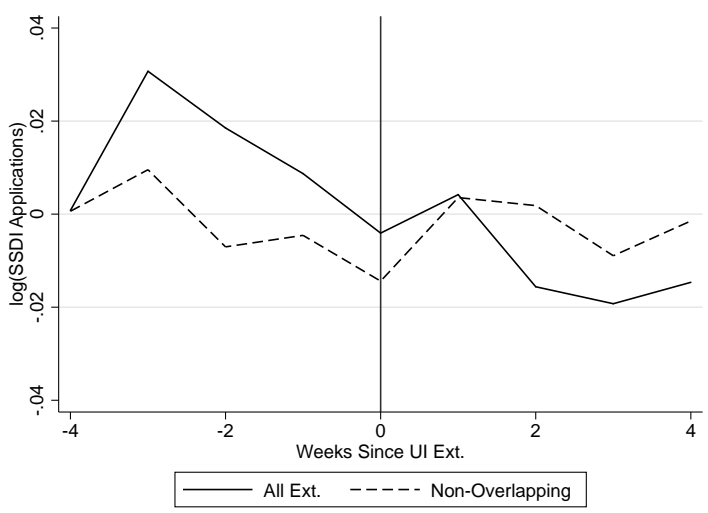

(c) Acceptance Rate - All Extensions

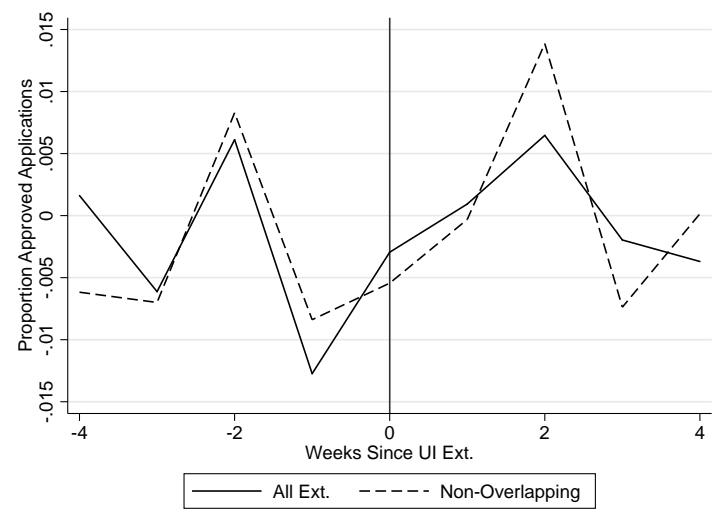

(b) $\log ($ SSDI Applications) - 13+ Week Extensions

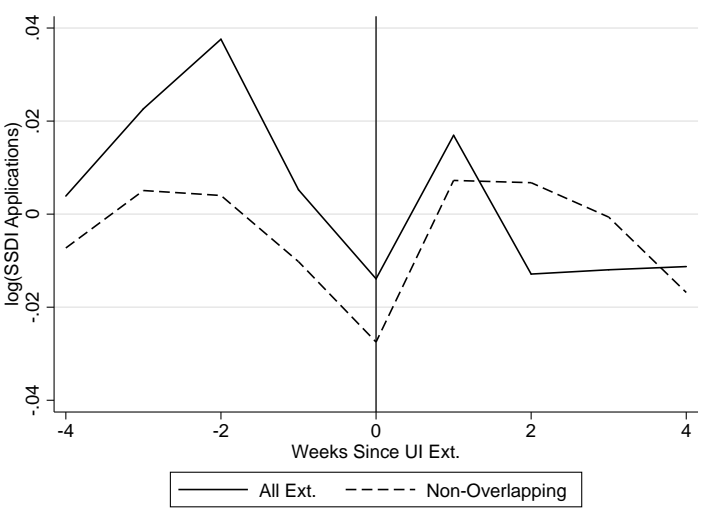

(d) Acceptance Rate - 13+ Week Extensions

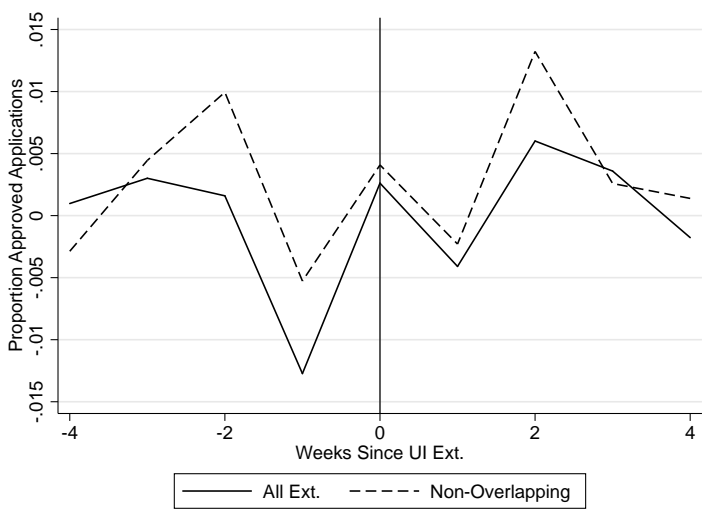

Notes: Figure reports coefficients on dummies for weeks before or after a UI extension from regressions that include state and week fixed effects and cubic polynomials in the insured unemployment rate and the total unemployment rate. Coefficients are reported in Appendix Tables A.2 and A.3. 
Figure 9. UI event studies (13+ week non-overlapping extensions), by age

(a) Log(SSDI Applications)

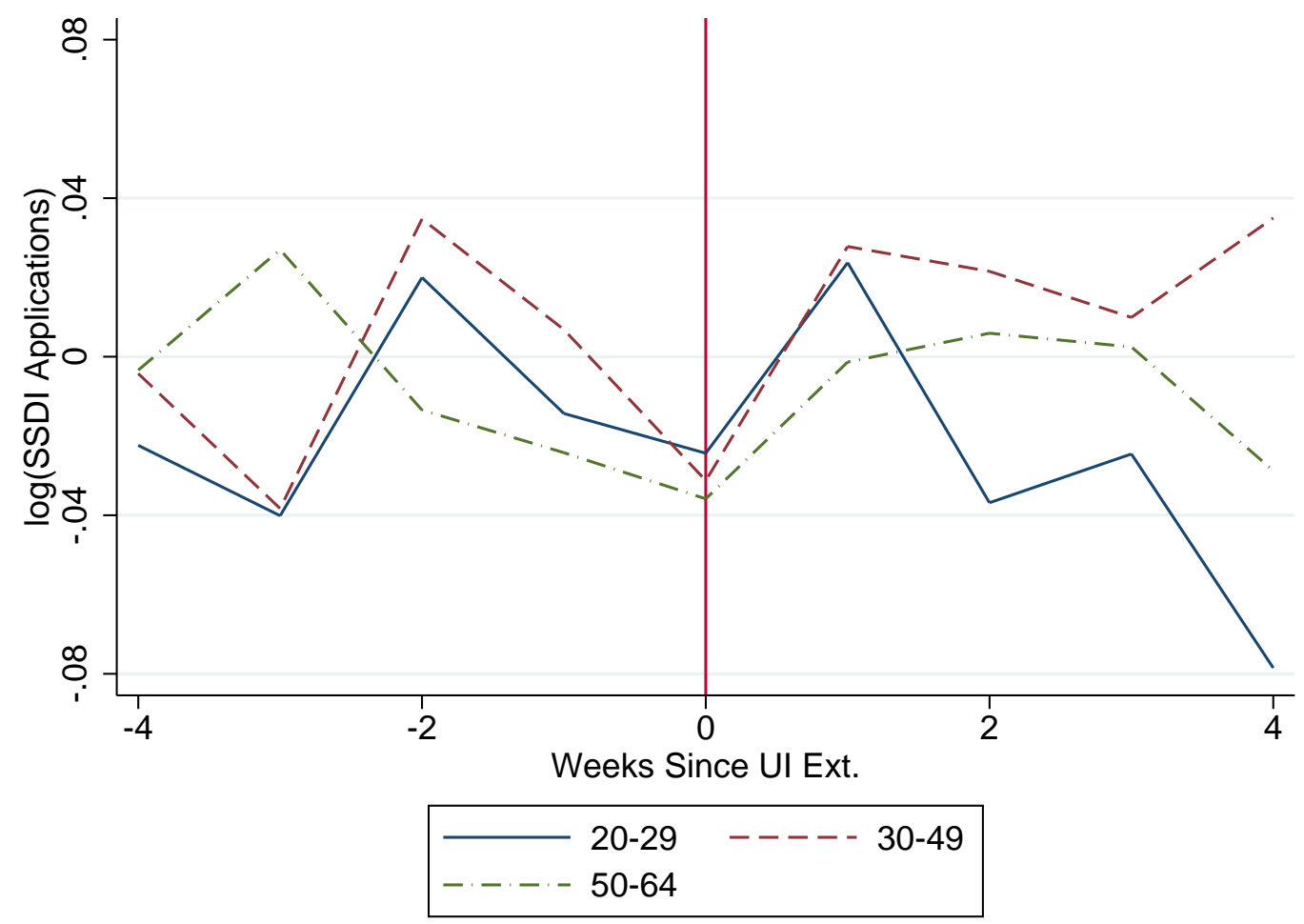

(b) Acceptance Rate

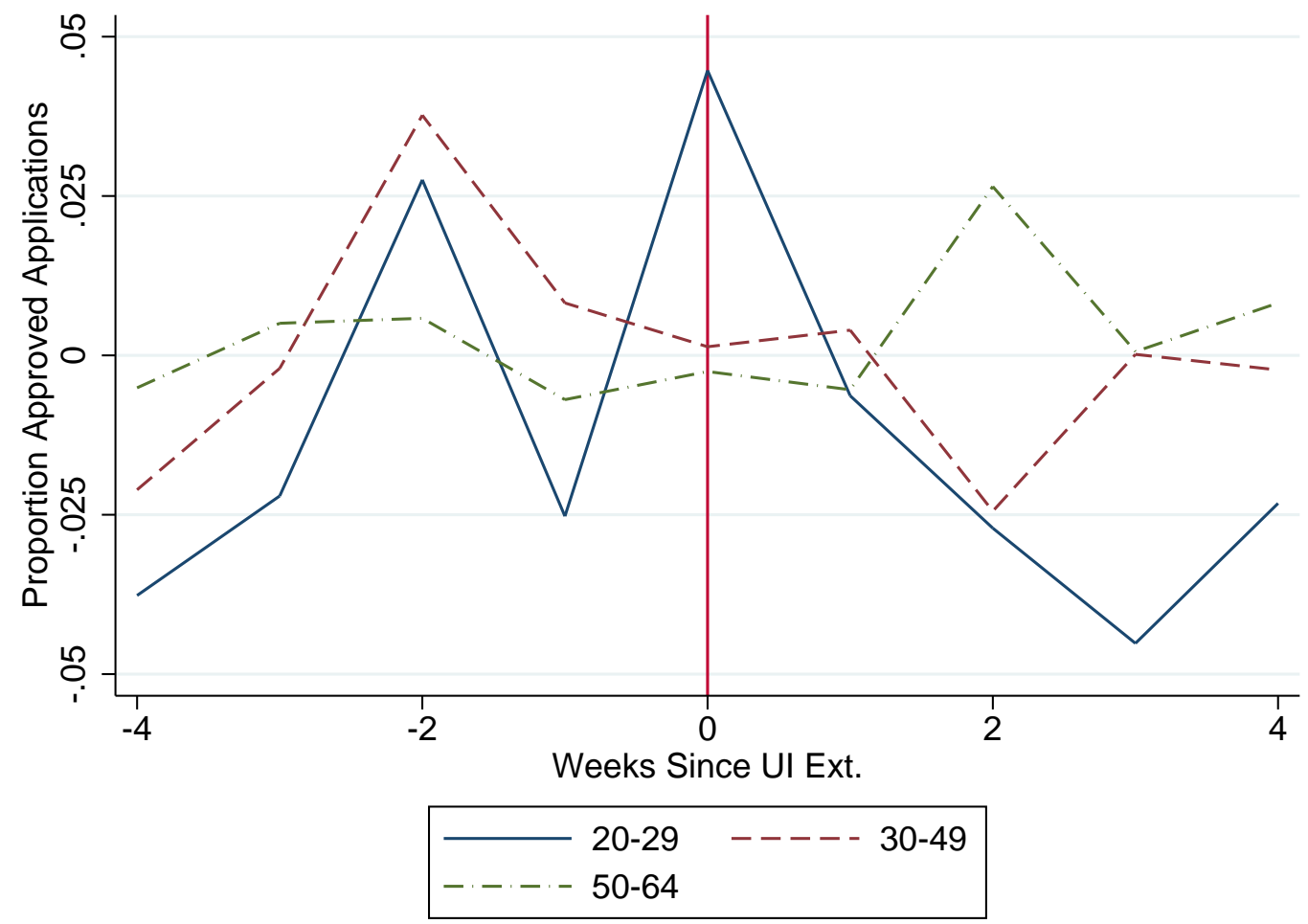

Notes: See notes to Figure 8. Coefficients are reported in Appendix Table A.4. 
Table 1. Time series analysis of national DI applications

\begin{tabular}{|c|c|c|c|c|c|c|c|c|}
\hline & $(1)$ & $(2)$ & (3) & (4) & (5) & (6) & (7) & (8) \\
\hline $\begin{array}{l}\text { Final UI exhaustions (index: } \\
\text { multiple of } 2005-7 \text { avg.) }\end{array}$ & $\begin{array}{l}-0.053 \\
(0.042)\end{array}$ & $\begin{array}{l}-0.038 \\
(0.024)\end{array}$ & $\begin{array}{c}0.015 \\
(0.008)\end{array}$ & $\begin{array}{c}0.014 \\
(0.008)\end{array}$ & $\begin{array}{c}0.018 \\
(0.009)\end{array}$ & & & \\
\hline $\begin{array}{c}\text { Exhaustions index (avg., } \\
\text { prev. } 3 \text { months) }\end{array}$ & & & & & $\begin{array}{l}-0.022 \\
(0.020)\end{array}$ & & & \\
\hline $\begin{array}{c}\text { Exhaustions index (avg., } \\
\text { next } 3 \text { months) }\end{array}$ & & & & & $\begin{array}{c}0.015 \\
(0.014)\end{array}$ & & & \\
\hline Initial UI exhaustions (index) & & & & & & $\begin{array}{l}-0.001 \\
(0.004)\end{array}$ & & \\
\hline UI final pays (index) & & & & & & & $\begin{array}{c}0.001 \\
(0.005)\end{array}$ & \\
\hline 1 (No exhaustions this month) & & & & & & & & $\begin{array}{l}-0.019 \\
(0.007)\end{array}$ \\
\hline Unemployment rate (SA) & & & $\begin{array}{c}0.039 \\
(0.003)\end{array}$ & $\begin{array}{c}0.037 \\
(0.005)\end{array}$ & $\begin{array}{c}0.031 \\
(0.005)\end{array}$ & $\begin{array}{c}0.036 \\
(0.005)\end{array}$ & $\begin{array}{c}0.036 \\
(0.005)\end{array}$ & $\begin{array}{c}0.037 \\
(0.006)\end{array}$ \\
\hline In(initial UI claims) & & & & $\begin{array}{l}-0.021 \\
(0.019)\end{array}$ & & $\begin{array}{l}-0.025 \\
(0.018)\end{array}$ & $\begin{array}{l}-0.025 \\
(0.019)\end{array}$ & $\begin{array}{l}-0.025 \\
(0.018)\end{array}$ \\
\hline 1(June, July, August 2010) & & & & $\begin{array}{c}0.023 \\
(0.008)\end{array}$ & & $\begin{array}{c}0.025 \\
(0.015)\end{array}$ & $\begin{array}{c}0.022 \\
(0.008)\end{array}$ & $\begin{array}{c}0.020 \\
(0.008)\end{array}$ \\
\hline Post-ARRA & & & & $\begin{array}{c}0.018 \\
(0.017)\end{array}$ & $\begin{array}{c}0.031 \\
(0.015)\end{array}$ & $\begin{array}{c}0.018 \\
(0.017)\end{array}$ & $\begin{array}{c}0.018 \\
(0.017)\end{array}$ & $\begin{array}{c}0.013 \\
(0.017)\end{array}$ \\
\hline $\begin{array}{l}\text { Quadratic time trend } \\
\mathrm{N}\end{array}$ & $\begin{array}{c}n \\
101\end{array}$ & $\begin{array}{c}y \\
101\end{array}$ & $\begin{array}{c}y \\
101\end{array}$ & $\begin{array}{c}y \\
101\end{array}$ & $\begin{array}{c}y \\
95\end{array}$ & $\begin{array}{c}y \\
101\end{array}$ & $\begin{array}{c}y \\
101\end{array}$ & $\begin{array}{c}y \\
101\end{array}$ \\
\hline
\end{tabular}

Notes: Sample in all columns is a national time series spanning August 2004 to December 2012 (November 2004 to September 2012 in column 5). Dependent variable is In(receipts for SSI, SSDI, or SSI/SSDI claims), measured at the monthly level and seasonally adjusted. Newey-West standard errors, allowing for autocorrelations at up to four lags, in parentheses. 
Table 2. Panel data regressions for SSDI applications at the state-month level

\begin{tabular}{|c|c|c|c|c|c|c|c|c|c|}
\hline & (1) & (2) & (3) & (4) & (5) & (6) & (7) & (8) & (9) \\
\hline \multirow[t]{2}{*}{ Unemployment rate (SA) } & 0.017 & & 0.016 & 0.016 & 0.016 & 0.017 & 0.017 & 0.018 & 0.017 \\
\hline & $(0.006)$ & & $(0.006)$ & $(0.006)$ & $(0.006)$ & $(0.006)$ & $(0.006)$ & $(0.006)$ & $(0.006)$ \\
\hline \multirow{2}{*}{$\begin{array}{l}\text { Final UI exhaustions (index: } \\
\text { multiple of } 2005-7 \text { avg.) }\end{array}$} & -0.002 & -0.003 & -0.003 & -0.004 & -0.003 & 0.000 & & & \\
\hline & $(0.003)$ & $(0.004)$ & $(0.003)$ & $(0.003)$ & $(0.002)$ & $(0.004)$ & & & \\
\hline \multirow{2}{*}{$\begin{array}{l}\text { Exhaustions index (avg., } \\
\text { prev. } 3 \text { months) }\end{array}$} & & & & 0.003 & & & & & \\
\hline & & & & $(0.005)$ & & & & & \\
\hline \multirow{2}{*}{$\begin{array}{l}\text { Exhaustions index (avg., } \\
\text { next } 3 \text { months) }\end{array}$} & & & & 0.005 & & & & & \\
\hline & & & & $(0.007)$ & & & & & \\
\hline \multirow[t]{2}{*}{ In(initial UI claims) } & & & 0.038 & & & & & & \\
\hline & & & $(0.032)$ & & & & & & \\
\hline \multirow[t]{2}{*}{ Initial UI exhaustions (index) } & & & & & & & 0.002 & & \\
\hline & & & & & & & $(0.002)$ & & \\
\hline \multirow[t]{2}{*}{ UI final pays (index) } & & & & & & & & 0.001 & \\
\hline & & & & & & & & $(0.002)$ & \\
\hline \multirow{2}{*}{\multicolumn{2}{|c|}{1 (No exhaustions this month) }} & & & & & & & & 0.010 \\
\hline & & & & & & & & & $(0.007)$ \\
\hline State FE & y & y & y & y & y & y & y & y & y \\
\hline Month FE & y & y & y & y & y & y & y & y & y \\
\hline Cubic UE rate control & & y & & & & & & & \\
\hline \multicolumn{3}{|c|}{3 leads and lags of exhaustion index } & & & y & & & & \\
\hline \multicolumn{3}{|l|}{ Exclude June-Aug 2010} & & & & y & & & \\
\hline $\mathrm{N}$ & 5,151 & 5,151 & 5,151 & 4,845 & 4,845 & 4,998 & 5,151 & 5,151 & 5,151 \\
\hline $\mathrm{R} 2$ & 0.991 & 0.991 & 0.991 & 0.991 & 0.991 & 0.991 & 0.991 & 0.991 & 0.991 \\
\hline
\end{tabular}

Notes: Dependent variable is In(receipts of SSI, SSDI, or SSI/SSDI claims), measured at the state-bymonth level and seasonally adjusted. Panel ranges from August 2004 to December 2012 (November 2004 to September 2012 in columns 4 and 5). Standard errors, clustered on the state, in parentheses. 
Table 3. Panel data regressions for approval rate at the state-month level

\begin{tabular}{lcccc}
\hline \hline & $\mathbf{( 1 )}$ & $\mathbf{( 2 )}$ & $\mathbf{( 3 )}$ & $\mathbf{( 4 )}$ \\
\hline Unemployment rate (SA) & -0.009 & -0.008 & -0.009 & -0.009 \\
& $(0.004)$ & $(0.004)$ & $(0.004)$ & $(0.004)$ \\
Final UI exhaustions & 0.001 & 0.000 & & \\
& $(0.001)$ & $(0.001)$ & & \\
Exhaustions index (avg., prev. 3 months) & & 0.008 & & \\
& & $(0.003)$ & & \\
Exhaustions index (avg., next 3 months) & & 0.000 & & \\
& & $(0.002)$ & & \\
Initial Ul exhaustions (index) & & -0.001 & \\
& & & & \\
UI final pays (index) & & & & \\
& & & & \\
State FE & & & & \\
Month FE & Yes & Yes & Yes & Yes \\
$\mathrm{N}$ & Yes & Yes & Yes & Yes \\
R2 & 1836 & 1836 & 1836 & 1836 \\
\hline \hline
\end{tabular}

Notes: Dependent variable is the approval rate of SSDI applications filed, measured at the state-bymonth level. Panel ranges from January 2008 - December 2010. Standard errors, clustered on the state, in parentheses. 
Table 4. Summary statistics for matched CPS-ASEC sample, 2005-2011

\begin{tabular}{|c|c|c|c|c|}
\hline & All & $\begin{array}{c}\text { Unemployed } \\
\text { at base } \\
\text { survey }\end{array}$ & $\begin{array}{l}\text { Unemployed } \\
\text { \& UI eligible }\end{array}$ & $\begin{array}{l}\text { Exhaust UI } \\
\text { before end of } \\
\text { calendar year }\end{array}$ \\
\hline & $(1)$ & (2) & (3) & \\
\hline $\mathrm{N}$ & 240,163 & 10,195 & 6,865 & 3,976 \\
\hline Female & $51 \%$ & $43 \%$ & $36 \%$ & $37 \%$ \\
\hline \multirow[t]{2}{*}{ Age } & 42.5 & 39.3 & 41.1 & 41.6 \\
\hline & {$[12.0]$} & {$[12.2]$} & [11.7] & [11.7] \\
\hline Age 50+ & $32 \%$ & $24 \%$ & $28 \%$ & $29 \%$ \\
\hline \multicolumn{5}{|l|}{ Education } \\
\hline LTHS & $10 \%$ & $16 \%$ & $16 \%$ & $17 \%$ \\
\hline HS & $31 \%$ & $39 \%$ & $41 \%$ & $40 \%$ \\
\hline Some college & $28 \%$ & $27 \%$ & $26 \%$ & $27 \%$ \\
\hline $\mathrm{BA}+$ & $31 \%$ & $18 \%$ & $17 \%$ & $16 \%$ \\
\hline \multicolumn{5}{|l|}{ Labor force status } \\
\hline Employed & $75 \%$ & $0 \%$ & $0 \%$ & $0 \%$ \\
\hline Unemployed & $5 \%$ & $100 \%$ & $100 \%$ & $100 \%$ \\
\hline Not in labor force (NILF) & $21 \%$ & $0 \%$ & $0 \%$ & $0 \%$ \\
\hline UI eligible & $3 \%$ & $67 \%$ & $100 \%$ & $100 \%$ \\
\hline Unemployment duration, years & & 1.32 & 1.31 & 1.46 \\
\hline (as of $12 / 31$ ) & & {$[0.56]$} & {$[0.54]$} & [0.63] \\
\hline UI expired before $12 / 31$ & & & $57.3 \%$ & $100.0 \%$ \\
\hline UI expired before $6 / 30$ & & & $36.7 \%$ & $64.1 \%$ \\
\hline Time since UI expiration, years & & & & 0.72 \\
\hline (as of $12 / 31$ ) & & & & {$[0.51]$} \\
\hline SSDI income in year $y$ & $3.2 \%$ & $1.4 \%$ & $1.2 \%$ & $1.4 \%$ \\
\hline SSDI income in year $y$ if none in $y-1$ & $1.4 \%$ & $1.0 \%$ & $0.9 \%$ & $1.1 \%$ \\
\hline
\end{tabular}

Notes: Standard deviations in square brackets. All statistics use sampling weights from the initial monthly CPS sample. 
Table 5. Analyses of SSDI receipt in matched CPS data

\begin{tabular}{|c|c|c|c|c|c|c|c|c|}
\hline & $\begin{array}{l}\text { All } \\
\text { (1) }\end{array}$ & (2) & (3) & (4) & (5) & (6) & $\begin{array}{c}\text { Unemp. } \\
(7)\end{array}$ & $\begin{array}{l}\text { Ul elig. } \\
\text { (8) }\end{array}$ \\
\hline \multicolumn{9}{|l|}{ Economic conditions } \\
\hline Unemployment rate & $\begin{array}{l}-0.003 \\
(0.008)\end{array}$ & $\begin{array}{l}-0.014 \\
(0.028)\end{array}$ & $\begin{array}{l}-0.018 \\
(0.030)\end{array}$ & $\begin{array}{l}-0.019 \\
(0.030)\end{array}$ & $\begin{array}{l}-0.019 \\
(0.030)\end{array}$ & $\begin{array}{c}0.400 \\
(0.246)\end{array}$ & $\begin{array}{l}-0.339 \\
(0.139)\end{array}$ & $\begin{array}{l}-0.345 \\
(0.184)\end{array}$ \\
\hline UR squared & & & & & & $\begin{array}{l}-0.062 \\
(0.033)\end{array}$ & & \\
\hline UR cubed & & & & & & $\begin{array}{c}0.003 \\
(0.001)\end{array}$ & & \\
\hline \multicolumn{9}{|c|}{ Individual labor force status (measured in spring) } \\
\hline Unemployed*Ul elig & & & $\begin{array}{c}1.09 \\
(0.14)\end{array}$ & $\begin{array}{c}0.05 \\
(0.32)\end{array}$ & $\begin{array}{l}-0.02 \\
(0.40)\end{array}$ & $\begin{array}{l}-0.02 \\
(0.40)\end{array}$ & & \\
\hline Unemployed*UI inelig & & & $\begin{array}{c}1.49 \\
(0.19)\end{array}$ & $\begin{array}{c}1.19 \\
(0.45)\end{array}$ & $\begin{array}{c}1.19 \\
(0.45)\end{array}$ & $\begin{array}{c}1.19 \\
(0.45)\end{array}$ & $\begin{array}{c}1.00 \\
(0.59)\end{array}$ & \\
\hline NILF - disabled & & & $\begin{array}{c}4.56 \\
(0.06)\end{array}$ & $\begin{array}{c}4.56 \\
(0.06)\end{array}$ & $\begin{array}{c}4.56 \\
(0.06)\end{array}$ & $\begin{array}{c}4.56 \\
(0.06)\end{array}$ & & \\
\hline NILF - non-disabled & & & $\begin{array}{c}2.09 \\
(0.07)\end{array}$ & $\begin{array}{c}2.09 \\
(0.07)\end{array}$ & $\begin{array}{c}2.09 \\
(0.07)\end{array}$ & $\begin{array}{c}2.09 \\
(0.07)\end{array}$ & & \\
\hline \multicolumn{3}{|c|}{ Unemp. duration (years)*UI elig } & & $\begin{array}{c}0.72 \\
(0.18)\end{array}$ & $\begin{array}{c}0.75 \\
(0.32)\end{array}$ & $\begin{array}{c}0.75 \\
(0.32)\end{array}$ & $\begin{array}{c}0.54 \\
(0.40)\end{array}$ & $\begin{array}{c}0.16 \\
(0.45)\end{array}$ \\
\hline \multicolumn{2}{|c|}{ Unemp. duration (years)*UI inelig. } & & & $\begin{array}{c}0.21 \\
(0.27)\end{array}$ & $\begin{array}{c}0.21 \\
(0.27)\end{array}$ & $\begin{array}{c}0.21 \\
(0.27)\end{array}$ & $\begin{array}{c}0.16 \\
(0.30)\end{array}$ & \\
\hline \multicolumn{9}{|l|}{ UI expiration } \\
\hline \multicolumn{2}{|c|}{$\begin{array}{l}\text { Time since UI expiration, years } \\
\text { (as of } 12 / 31 \text { ) }\end{array}$} & & & & $\begin{array}{l}-0.17 \\
(0.43)\end{array}$ & $\begin{array}{l}-0.17 \\
(0.43)\end{array}$ & $\begin{array}{l}0.07 \\
(0.53)\end{array}$ & $\begin{array}{c}0.32 \\
(0.55)\end{array}$ \\
\hline UI expired before $6 / 30$ & & & & & $\begin{array}{c}0.25 \\
(0.43)\end{array}$ & $\begin{array}{c}0.25 \\
(0.43)\end{array}$ & $\begin{array}{c}0.14 \\
(0.46)\end{array}$ & $\begin{array}{c}0.26 \\
(0.49)\end{array}$ \\
\hline $\mathrm{N}$ & 232,998 & 232,998 & 232,998 & 232,998 & 232,998 & 232,998 & 9,217 & 4,832 \\
\hline \multicolumn{9}{|c|}{ Average probability of DI receipt among (initially) unemployed, in p.p. } \\
\hline & 0.97 & 0.97 & 0.97 & 0.97 & 0.97 & 0.97 & 1.06 & 1.27 \\
\hline \multicolumn{9}{|l|}{ Effect of (in p.p.): } \\
\hline Own unemployment & & & 0.68 & 0.68 & 0.67 & 0.67 & 0.59 & 0.19 \\
\hline Ul expiration & & & & & 0.01 & 0.01 & 0.07 & 0.32 \\
\hline
\end{tabular}

Notes: Table reports coefficients (and standard errors) from logit models. Dependent variable is an indicator for receipt of SSDI income during the calendar year, as reported on the ASEC. All specifications include state \& month FEs and demographic controls (age, 4 age group dummies, and gender). Sample spans calendar years 2005-2011. Individual labor force status is drawn from the baseline monthly CPS sample. Unemployment duration and expiration are measured as of December 31 of the year. Counterfactual effects in bottom rows set $\mathrm{UI}$ expiration date to after the end of the year or own labor force status to employed (with unemployment duration of zero) 


\section{Appendix}

Our time series and panel data analyses rely on a measure of simulated UI exhaustions. This appendix describes the simulation.

We begin with data at the state-week level on initial claims for UI payments, as reported by the Employment and Training Administration (ETA). We denote these as $\mathrm{IC}_{\mathrm{sw}}$.

Initial claims substantially overstate the number of actual recipients, in part because some claimants are ruled ineligible for benefits. On average, a bit less than half as many initial payments are made as there are initial claims filed.

Unfortunately, ETA does not publish weekly state-level data on initial payments. They do publish monthly data, however. We compute the ratio of initial payments to initial claims at the state-by-month level, and denote it $\mathrm{F}_{\mathrm{sm}}$. We estimate the number of initial payments in week w of month $\mathrm{m}(\mathrm{w})$ as $\mathrm{IC}_{\mathrm{sw}}{ }^{*} \mathrm{~F}_{\mathrm{s}, \mathrm{m}}(\mathrm{w})$.

Next, we calculate the date at which an individual who makes an initial claim in state $\mathrm{s}$ in week $\mathrm{w}$ will exhaust his benefits, $\mathrm{e}(\mathrm{s}, \mathrm{w})$. We use our database of UI rules for this, assuming that all recipients are eligible for the full duration of benefits and that they draw benefits continuously from w until exhaustion.

As noted in the text, we consider two definitions of exhaustion: The first week in which benefits are not received at the usual time, and the first week in which they are not received either initially or retroactively. The distinction arises from the temporary expirations of the EUC program in 2010: Many recipients are counted as exhausting during these expirations by the first definition but afterward by the second. Most of our analysis uses the second definition. 
There are cases where recipients exhaust their benefits, experience periods of non-payments, then become eligible for additional benefits later. This can happen when new EUC tiers are added for which past exhaustees are eligible. It can also arise for EB recipients during and after the 2010 temporary EUC expirations: Many states ended EB payments during these expirations, then rejoined when the program was reauthorized (and the 100\% federal EB share simultaneously reinstated). Recipients whose EB payments were interrupted were not repaid retroactively. Both of our definitions count these recipients as having exhausted their benefits on the first week for which benefits were not paid.

Of course, most claimants do not remain in unemployment until exhaustion, either because they get jobs beforehand or because they exit the labor force. We estimate the probability that an individual who drew his initial payment in week w survives to exhaust his benefits $d=e(s, w)-w$ weeks later as

$$
\mathrm{S}(\mathrm{d} ; \mathrm{s}, \mathrm{w})=\prod_{t=0}^{d-1}(1-\lambda(s, d, w+d))
$$

where $\lambda(s, d, v)$ represents the probability that an individual in state s with unemployment duration d in week v exits unemployment (by finding a new job or by exiting the labor force) by week $v+1$.

To estimate the hazard function, we begin with monthly data on initial and final payments in the regular UI program, which offers 26 weeks of benefits. Let $\mathrm{p}_{\mathrm{m}}$ represent the ratio of final payments in month $m+5$ to initial payments in month $m$, computed for the nation as a whole. This can be seen as an estimate of the 26-week survival probability. We smooth it by estimating a time series regression of $\mathrm{p}_{\mathrm{m}}$ on a $5^{\text {th }}$ order polynomial in calendar time, with month-of-year (seasonality) effects 
removed. Let the fitted value (net of the seasonality effects) be $\hat{p}_{m}$. Our initial estimate of the hazard is based on the $26^{\text {th }}$ root of this:

(A2) $\lambda^{0}(s, d, v)=1-\left(\hat{p}_{m(v)+3}\right)^{1 / 26}$.

Here, $\mathrm{m}(\mathrm{v})$ is the month containing week $\mathrm{v}$; we shift this by 3 to capture the month in the midpoint of the period covered by the six-month survival data.

Note that this initial hazard estimate does not vary with duration of unemployment, where the evidence indicates that unemployment exit hazards are higher for the short-term unemployed than for the long-term unemployed. We draw estimates of the duration profile from Rothstein's (2011) analysis of exit hazards in CPS data, as summarized by his Figure 5. We use the CPS data to compute exit hazards for three duration groups $(d<13,13 \leq d<26$, and $d \geq 26)$ relative to the average exit hazard over the first 26 weeks, treating the periods before and after January 1, 2008 separately. By comparing the exit hazard in each duration group to the average exit hazard for those with $d<26$, we obtain multiplicative factors for use in adjusting $\lambda^{0}$. These lead us to our adjusted hazards:

$$
\lambda(s, d, v)= \begin{cases}1.049 * \lambda^{0}(s, d, v) & \text { if } d<13 \text { and } v<1 / 1 / 2008 \\ 1.081 * \lambda^{0}(s, d, v) & \text { if } d<13 \text { and } v \geq 1 / 1 / 2008 \\ 0.723 * \lambda^{0}(s, d, v) & \text { if } 13 \leq d<26 \text { and } v<1 / 1 / 2008 \\ 0.691 * \lambda^{0}(s, d, v) & \text { if } 13 \leq d<26 \text { and } v \geq 1 / 1 / 2008 \\ 0.760 * \lambda^{0}(s, d, v) & \text { if } 26 \leq d \text { and } v<1 / 1 / 2008 \\ 0.610 * \lambda^{0}(s, d, v) & \text { if } 26 \leq d \text { and } v \geq 1 / 1 / 2008\end{cases}
$$

Our final simulated UI exhaustion measure for state $s$, week $t$ is combines initial claims, payment rates, and survival to exhaustion. Formally, it is:

(A4) $E_{s t}=\sum_{e(s, w)=t} \mathrm{IC}_{s w} * \mathrm{~F}_{s, m(w)} * \prod_{i=0}^{e(s, w)-w-1}(1-\lambda(s, i, w+i))$. 
Table A.1 Panel data regressions for SSDI applications at the state-month level, comparing results with different data sources and time periods

\begin{tabular}{|c|c|c|c|c|c|c|c|c|c|c|c|c|}
\hline & \multicolumn{4}{|c|}{$\begin{array}{l}\text { Published data } \\
\text { Full sample }\end{array}$} & \multicolumn{4}{|c|}{$\begin{array}{c}\text { Published data } \\
\text { 2008-2010 }\end{array}$} & \multicolumn{4}{|c|}{$\begin{array}{c}\text { Administrative files } \\
2008-2010\end{array}$} \\
\hline & (1) & (2) & (3) & (4) & (5) & (6) & (7) & (8) & (9) & (10) & (11) & $(12)$ \\
\hline Unemployment rate (SA) & 0.017 & 0.016 & 0.017 & 0.017 & 0.009 & 0.007 & 0.011 & 0.010 & 0.007 & 0.006 & 0.007 & 0.007 \\
\hline \multirow[t]{2}{*}{ Final UI exhaustions } & -0.002 & -0.004 & & & -0.011 & -0.010 & & & 0.000 & 0.000 & & \\
\hline & $(0.003)$ & $(0.003)$ & & & $(0.005)$ & $(0.004)$ & & & $(0.002)$ & $(0.001)$ & & \\
\hline \multirow{2}{*}{$\begin{array}{l}\text { Exhaustions index (avg. , } \\
\text { next } 3 \text { months) }\end{array}$} & & 0.005 & & & & 0.000 & & & & 0.003 & & \\
\hline & & $(0.007)$ & & & & $(0.007)$ & & & & $(0.004)$ & & \\
\hline \multirow[t]{2}{*}{ Initial UI exhaustions (index) } & & & 0.002 & & & & 0.000 & & & & 0.001 & \\
\hline & & & $(0.002)$ & & & & $(0.001)$ & & & & $(0.001)$ & \\
\hline Ul final pays (index) & & & & 0.001 & & & & 0.000 & & & & -0.001 \\
\hline R2 & 0.991 & 0.991 & 0.991 & 0.991 & 0.994 & 0.994 & 0.994 & 0.994 & 0.997 & 0.997 & 0.997 & 0.997 \\
\hline
\end{tabular}

Notes: Dependent variable in Columns 1-8 is In(receipts for SSI, SSDI, or SSI/SSDI claims) from publicly available tabulations by state and month; dependent variable in Columns 9-12 is In(applications for SSDI) compiled from administrative micro data files. Panel ranges from August 2004 - December 2012 for Columns 1-4 and from January 2008 - December 2010 for the remaining columns. Standard errors, clustered on the state, in parentheses. 
Table A.2 Event study regressions for In(number of SSDI applications)

\begin{tabular}{|c|c|c|c|c|c|c|c|c|}
\hline & \multicolumn{2}{|c|}{ (1) } & \multicolumn{2}{|c|}{$(2)$} & \multicolumn{2}{|c|}{ (3) } & \multicolumn{2}{|c|}{ (4) } \\
\hline & $\mathrm{b} / \mathrm{se}$ & p-value & $\mathrm{b} / \mathrm{se}$ & p-value & b/se & p-value & b/se & p-value \\
\hline \multirow[t]{2}{*}{ Week of Extension } & -0.004 & {$[0.095]$} & -0.014 & {$[0.360]$} & -0.014 & {$[0.035]$} & -0.027 & {$[0.111]$} \\
\hline & $(0.010)$ & & (0.015) & & $(0.015)$ & & (0.016) & \\
\hline \multirow[t]{2}{*}{1 Week Post Extension } & 0.004 & [0.319] & 0.004 & {$[0.680]$} & 0.017 & {$[0.973]$} & 0.007 & [0.399] \\
\hline & $(0.010)$ & & (0.009) & & $(0.013)$ & & (0.010) & \\
\hline \multirow[t]{2}{*}{2 Weeks Post Extension } & -0.016 & {$[0.015]$} & 0.002 & [0.911] & -0.013 & {$[0.053]$} & 0.007 & {$[0.675]$} \\
\hline & $(0.012)$ & & $(0.017)$ & & $(0.016)$ & & $(0.020)$ & \\
\hline \multirow[t]{2}{*}{3 Weeks Post Extension } & -0.019 & {$[0.002]$} & -0.009 & {$[0.435]$} & -0.012 & [0.033] & -0.001 & [0.909] \\
\hline & $(0.010)$ & & $(0.012)$ & & $(0.015)$ & & $(0.014)$ & \\
\hline \multirow[t]{2}{*}{4 Weeks Post Extension } & -0.015 & {$[0.052]$} & -0.001 & [0.939] & -0.011 & {$[0.123]$} & -0.017 & [0.374] \\
\hline & $(0.012)$ & & $(0.012)$ & & $(0.017)$ & & (0.017) & \\
\hline \multirow[t]{2}{*}{1 Week Pre Extension } & 0.009 & & -0.005 & & 0.005 & & -0.010 & \\
\hline & $(0.013)$ & & $(0.012)$ & & $(0.014)$ & & $(0.012)$ & \\
\hline \multirow[t]{2}{*}{2 Weeks Pre Extension } & 0.019 & & -0.007 & & 0.038 & & 0.004 & \\
\hline & $(0.012)$ & & $(0.014)$ & & $(0.012)$ & & (0.010) & \\
\hline \multirow[t]{2}{*}{3 Weeks Pre Extension } & 0.031 & & 0.010 & & 0.023 & & 0.005 & \\
\hline & $(0.014)$ & & $(0.017)$ & & $(0.016)$ & & (0.016) & \\
\hline \multirow[t]{2}{*}{4 Weeks Pre Extension } & 0.001 & & 0.001 & & 0.004 & & -0.007 & \\
\hline & $(0.010)$ & & $(0.016)$ & & $(0.011)$ & & $(0.016)$ & \\
\hline \multicolumn{9}{|l|}{ Difference in Average (0 to 4 vs -1} \\
\hline to -4$)$ & -0.025 & & -0.004 & & -0.024 & & -0.004 & \\
\hline P-Value & [0.026] & & [0.911] & & {$[0.064]$} & & [0.498] & \\
\hline Average ( 0 to 4 weeks) & -0.010 & & -0.004 & & -0.007 & & -0.006 & \\
\hline P-Value & {$[0.414]$} & & {$[0.91]$} & & {$[0.211]$} & & [0.468] & \\
\hline Non-Overlapping Extensions Only & No & & Yes & & No & & Yes & \\
\hline 13+ Week Extensions Only & No & & No & & Yes & & Yes & \\
\hline State FE & $x$ & & $x$ & & $x$ & & $x$ & \\
\hline Time FE & $x$ & & $x$ & & $x$ & & $x$ & \\
\hline Cubic in Insured Unemp. Rate & $x$ & & $x$ & & $x$ & & $x$ & \\
\hline Cubic in Unemployment Rate (SA) & $x$ & & $x$ & & $x$ & & $x$ & \\
\hline $\mathrm{N}$ & 8007 & & 8007 & & 8007 & & 8007 & \\
\hline $\mathrm{R} 2$ & 0.989 & & 0.989 & & 0.989 & & 0.989 & \\
\hline
\end{tabular}

Notes: Dependent variable is In(SSDI applications), measured at the state-by-week level. Panel ranges from January 2008 - December 2010. Standard errors, clustered on the state, in parentheses. $\mathrm{P}$-values of tests of post-extension dummies against the average of pre-extension dummies are in squared brackets. 
Table A.3 Event study regressions for acceptance rate

\begin{tabular}{|c|c|c|c|c|c|c|c|c|}
\hline & \multicolumn{2}{|c|}{ (1) } & \multicolumn{2}{|c|}{$(2)$} & \multicolumn{2}{|c|}{ (3) } & \multicolumn{2}{|c|}{ (4) } \\
\hline & b/se & p-value & b/se & p-value & b/se & p-value & b/se & p-value \\
\hline \multirow[t]{2}{*}{ Week of Extension } & -0.003 & {$[0.970]$} & -0.005 & {$[0.787]$} & 0.003 & {$[0.424]$} & 0.004 & {$[0.794]$} \\
\hline & $(0.004)$ & & $(0.008)$ & & $(0.005)$ & & $(0.010)$ & \\
\hline \multirow[t]{2}{*}{1 Week Post Extension } & 0.001 & {$[0.368]$} & 0.000 & {$[0.604]$} & -0.004 & [0.669] & -0.002 & [0.520] \\
\hline & $(0.006)$ & & $(0.005)$ & & $(0.006)$ & & $(0.006)$ & \\
\hline \multirow[t]{2}{*}{2 Weeks Post Extension } & 0.006 & [0.157] & 0.014 & [0.023] & 0.006 & {$[0.240]$} & 0.013 & [0.117] \\
\hline & $(0.008)$ & & $(0.007)$ & & $(0.007)$ & & $(0.006)$ & \\
\hline \multirow[t]{2}{*}{3 Weeks Post Extension } & -0.002 & [0.881] & -0.007 & {$[0.630]$} & 0.004 & {$[0.350]$} & 0.003 & [0.899] \\
\hline & $(0.006)$ & & $(0.009)$ & & $(0.006)$ & & $(0.008)$ & \\
\hline \multirow[t]{2}{*}{4 Weeks Post Extension } & -0.004 & {$[0.854]$} & 0.000 & [0.519] & -0.002 & [0.998] & 0.001 & [0.983] \\
\hline & $(0.006)$ & & $(0.005)$ & & $(0.006)$ & & $(0.008)$ & \\
\hline \multirow[t]{2}{*}{1 Week Pre Extension } & -0.013 & & -0.008 & & -0.013 & & -0.005 & \\
\hline & $(0.005)$ & & $(0.005)$ & & $(0.006)$ & & $(0.006)$ & \\
\hline \multirow[t]{2}{*}{2 Weeks Pre Extension } & 0.006 & & 0.008 & & 0.002 & & 0.010 & \\
\hline & $(0.005)$ & & $(0.006)$ & & $(0.006)$ & & $(0.008)$ & \\
\hline \multirow[t]{2}{*}{3 Weeks Pre Extension } & -0.006 & & -0.007 & & 0.003 & & 0.004 & \\
\hline & $(0.004)$ & & $(0.004)$ & & $(0.005)$ & & $(0.006)$ & \\
\hline \multirow[t]{2}{*}{4 Weeks Pre Extension } & 0.002 & & -0.006 & & 0.001 & & -0.003 & \\
\hline & $(0.007)$ & & $(0.005)$ & & $(0.006)$ & & $(0.005)$ & \\
\hline \multicolumn{9}{|l|}{ Difference in Average (0 to 4 vs -1} \\
\hline to -4$)$ & 0.003 & & 0.003 & & 0.003 & & 0.002 & \\
\hline P-Value & {$[0.706]$} & & {$[0.218]$} & & [0.283] & & {$[0.47]$} & \\
\hline Average ( 0 to 4 weeks) & 0.000 & & 0.000 & & 0.001 & & 0.004 & \\
\hline P-Value & {$[0.636]$} & & [0.352] & & [0.398] & & [0.289] & \\
\hline Non-Overlapping Extensions Only & No & & Yes & & No & & Yes & \\
\hline 13+ Week Extensions Only & No & & No & & Yes & & Yes & \\
\hline State FE & $x$ & & $x$ & & $x$ & & $x$ & \\
\hline Time FE & $x$ & & $x$ & & $x$ & & $x$ & \\
\hline Cubic in Insured Unemp. Rate & $x$ & & $x$ & & $x$ & & $x$ & \\
\hline Cubic in Unemployment Rate (SA) & $x$ & & $x$ & & $x$ & & $x$ & \\
\hline $\mathrm{N}$ & 8007 & & 8007 & & 8007 & & 8007 & \\
\hline $\mathrm{R} 2$ & 0.72 & & 0.73 & & 0.72 & & 0.73 & \\
\hline
\end{tabular}

Notes: Dependent variable is the acceptance rate, measured at the state-by-week level. Panel ranges from January 2008 - December 2010. Standard errors, clustered on the state, in parentheses. P-values of tests of post-extension dummies against the average of pre-extension dummies are in squared brackets. 
Table A.4 Event study regressions for In(number of SSDI applications) and acceptance rate by age group

\begin{tabular}{|c|c|c|c|c|c|c|}
\hline & \multicolumn{2}{|c|}{ Age 20-29 } & \multicolumn{2}{|c|}{ Age 30-49 } & \multicolumn{2}{|c|}{ Age 50-65 } \\
\hline & (1) & (2) & (3) & (4) & (5) & (6) \\
\hline \multirow[t]{2}{*}{ Week of Extension } & -0.024 & 0.045 & -0.031 & 0.001 & -0.036 & -0.003 \\
\hline & $(0.055)$ & $(0.026)$ & $(0.027)$ & $(0.015)$ & $(0.023)$ & $(0.011)$ \\
\hline \multirow[t]{2}{*}{1 Week Post Extension } & 0.024 & -0.006 & 0.028 & 0.004 & -0.001 & -0.005 \\
\hline & $(0.062)$ & $(0.034)$ & $(0.027)$ & $(0.013)$ & $(0.014)$ & $(0.008)$ \\
\hline \multirow[t]{2}{*}{2 Weeks Post Extension } & -0.037 & -0.027 & 0.022 & -0.024 & 0.006 & 0.026 \\
\hline & $(0.063)$ & $(0.040)$ & $(0.034)$ & $(0.016)$ & $(0.021)$ & $(0.009)$ \\
\hline \multirow[t]{2}{*}{3 Weeks Post Extension } & -0.025 & -0.045 & 0.010 & 0.000 & 0.002 & 0.001 \\
\hline & $(0.056)$ & $(0.028)$ & $(0.025)$ & $(0.013)$ & $(0.016)$ & $(0.010)$ \\
\hline \multirow[t]{2}{*}{4 Weeks Post Extension } & -0.079 & -0.023 & 0.035 & -0.002 & -0.029 & 0.008 \\
\hline & $(0.053)$ & $(0.029)$ & $(0.027)$ & $(0.017)$ & $(0.026)$ & $(0.007)$ \\
\hline \multirow[t]{2}{*}{1 Week Pre Extension } & -0.014 & -0.025 & 0.007 & 0.008 & -0.024 & -0.007 \\
\hline & $(0.048)$ & $(0.024)$ & $(0.022)$ & $(0.013)$ & $(0.017)$ & $(0.007)$ \\
\hline \multirow[t]{2}{*}{2 Weeks Pre Extension } & 0.020 & 0.028 & 0.035 & 0.038 & -0.013 & 0.006 \\
\hline & $(0.047)$ & $(0.026)$ & $(0.021)$ & $(0.012)$ & $(0.015)$ & $(0.010)$ \\
\hline \multirow[t]{2}{*}{3 Weeks Pre Extension } & -0.040 & -0.022 & -0.038 & -0.002 & 0.027 & 0.005 \\
\hline & $(0.051)$ & $(0.032)$ & $(0.036)$ & $(0.022)$ & $(0.016)$ & $(0.006)$ \\
\hline \multirow[t]{2}{*}{4 Weeks Pre Extension } & -0.022 & -0.038 & -0.004 & -0.021 & -0.003 & -0.005 \\
\hline & $(0.058)$ & $(0.029)$ & $(0.032)$ & $(0.014)$ & $(0.018)$ & $(0.006)$ \\
\hline \multicolumn{7}{|l|}{ Difference in Average (0 to 4 vs -1} \\
\hline to -4$)$ & -0.014 & 0.003 & 0.013 & -0.01 & -0.008 & 0.006 \\
\hline P-Value of Joint Significance test & {$[0.862]$} & {$[0.245]$} & {$[0.490$ ] } & {$[0.583]$} & {$[0.737]$} & {$[0.037]$} \\
\hline Difference in Average ( 0 to 4 vs 0 ) & -0.028 & -0.011 & 0.013 & -0.004 & -0.012 & 0.005 \\
\hline P-Value of Joint Significance test & {$[0.747]$} & {$[0.430]$} & {$[0.463]$} & {$[0.590]$} & [ 0.672 ] & {$[0.016]$} \\
\hline Non-Overlapping Extensions Only & Yes & Yes & Yes & Yes & Yes & Yes \\
\hline 13+ Week Extensions Only & Yes & Yes & Yes & Yes & Yes & Yes \\
\hline State FE & $x$ & $x$ & $x$ & $x$ & $x$ & $x$ \\
\hline Time FE & $x$ & $x$ & $x$ & $x$ & $x$ & $x$ \\
\hline Cubic in Insured Unemp. Rate & $x$ & $x$ & $x$ & $x$ & $x$ & $x$ \\
\hline Cubic in Unemployment Rate (SA) & $x$ & $x$ & $x$ & $x$ & $x$ & $x$ \\
\hline $\mathrm{N}$ & 7620 & 7620 & 8003 & 8003 & 8007 & 8007 \\
\hline $\mathrm{R} 2$ & 0.86 & 0.18 & 0.97 & 0.54 & 0.98 & 0.53 \\
\hline
\end{tabular}

Notes: Dependent variable is In(number of SSDI applications) for columns 1, 3 and 5 and the acceptance rate for columns 2, 4 and 6. Panel ranges from January 2008 - December 2010. Standard errors, clustered on the state, in parentheses. P-values of tests of post-extension dummies against the average of pre-extension dummies are in squared brackets. 